\title{
Eco-Friendly Cutting Fluids in Minimum Quantity Lubrication Assisted Machining: A Review on the Perception of Sustainable Manufacturing
}

\author{
Binayak Sen ${ }^{1} \cdot$ Mozammel Mia $^{2,5} \cdot$ G. M. Krolczyk ${ }^{3} \cdot$ Uttam Kumar Mandal $^{1} \cdot$ Sankar Prasad Mondal $^{4}$
}

Received: 13 August 2018 / Revised: 20 September 2019 / Accepted: 26 September 2019 / Published online: 15 October 2019

(c) The Author(s) 2019

\begin{abstract}
In modern days, the conception of sustainability has progressively advanced and has begun receiving global interest. Thus, sustainability is an imperative idea in modern research. Considering the recent trend, this review paper presents a summary of the previously published research articles on minimum quantity lubrication (MQL) assisted machining. The requirement to stir towards sustainability motivated the researchers to revise the effects of substitute lubrication methods on the machining. Conventional lubri-cooling agents are still extensively employed when machining of engineering alloys, but the majority of the recent papers have depicted that the utilization of vegetable oil, nanofluids, and nanoplatelets in MQL system confers superior machining performances as compared to conventional lubrication technology. In actual, the definite principle of this manuscript is to re-examine modern advancements in the MQL technique and also explore the benefits of the vegetable oil and nanofluid as a lubricant. In brief, this paper is a testimony to the advancing capabilities of eco-friendly MQL technique which is a viable alternative to the flood lubrication technology, and the outcomes of this review work can be contemplated as a movement towards sustainable machining.
\end{abstract}

Keywords MQL $\cdot$ Vegetable oils · Nanofluids $\cdot$ Sustainable manufacturing

$\begin{array}{ll}\text { Abbreviations } \\ \text { MQL } & \text { Minimum quantity lubrication } \\ \text { BUE } & \text { Built up edge } \\ \text { ISO } & \text { Indian standard organization } \\ \text { B.D.P.F } & \text { Benefit drawback precaution future scope } \\ \text { VMQL } & \text { Vegetable oil in MQL assisted machining } \\ \text { NMQL } & \text { Nanofluids in MQL assisted machining } \\ \text { OSHA } & \text { Occupational safety and health administration }\end{array}$

G. M. Krolczyk

g.krolczyk@po.opole.pl

Mozammel Mia

m.mia19@imperial.ac.uk; mozammelmiaipe@gmail.com

1 Production Engineering, National Institute of Technology, Agartala 799046, India

2 Mechanical and Production Engineering, Ahsanullah University of Science and Technology, Dhaka, Bangladesh

3 Opole University of Technology, 76 Proszkowska St, 45-758 Opole, Poland

4 Department of Natural Science, Maulana Abul Kalam Azad University of Technology, Haringhata 741249, West Bengal, India

5 Department of Mechanical Engineering, Imperial College London, South Kensington, London, UK

$\begin{array}{ll}\text { EPA } & \text { Environmental protection agency } \\ \text { TEM } & \text { Transmission electron microscopy } \\ \text { FT-IR } & \text { Fourier-transform infrared spectroscopy } \\ \text { TGA } & \text { Thermogravimetric analysis } \\ \text { MWCNT } & \text { Multiwall carbon nano-tube } \\ \text { CBN } & \text { Cubic boron nitride } \\ \text { LCA } & \text { Life cycle assessment } \\ \text { EB } & \text { Ecological burden } \\ \text { RHVT } & \text { Ranque-Hilsch vortex tube } \\ \text { scCO }_{2} & \text { Supercritical carbon dioxide } \\ \text { NIOSH } & \text { National institute for occupational safety and } \\ & \text { health } \\ \text { SEM } & \text { Scanning electron microscopy } \\ \text { XRD } & \text { X-ray diffraction } \\ \text { DLS } & \text { Dynamic light scattering } \\ \text { FEM } & \text { Finite element method }\end{array}$

\section{Introduction}

\subsection{Machining: Past Legacy and Present Challenges}

Reportedly, machining is the most flexible mechanized procedure where the desired size, shape and surface finish can 
be accomplished by the elimination of excessive materials in the shape of little chips or flakes. Owing to which, in previous decades, we have observed abundant researches on the various lubricating systems, which enhanced the efficiency of the machining processes. During machining of modern alloys, extreme heat energy, and cutting forces are generated which leads to poor surface quality and increases the tool wear possibility $[1,2]$. Hence, the machining of modern alloys remains a costly task because of low productivity complication [3]. The usual alternative in the mechanized industry to manage the tool-workpiece friction and temperature throughout machining is the use of cutting fluids. However, Weinert et al. [4] examined that the employment of cutting fluids inadequately influences the atmosphere and human health equally. Thus, the manufacturing industries are looking for a technique which minimizes the utilization of lubricants throughout the metal cutting process due to financial and ecological anxieties. The general intention of the standards in the ISO 14000 is to shield environmental instability through socioeconomic prerequisites. That said, the industries need signing up for five fundamentals, namely, the water pollution, land pollution, management of waste, harmful air emissions, and natural sources and raw material conservation [5, 6]. Consequently, an efficient system of coolant employment is demanded that simultaneously reduces the consumption of coolants and improves the productivity-here MQL comes out as a substitute which can be contemplated in detail to get the preferred goal.

\subsection{MQL and MQCL Technology}

The theory of MQL was recommended by different researchers for dealing with the concerns of biological safety. The philosophy of MQL advocated that the minimum utilization of cutting fluid is very much advantageous in terms of the economy because it significantly minimizes the lubrication cost [7]. MQL, also famous as "Near-dry machining" [8], Small quantity lubrication $[9,10]$ and "Micro lubrication," [11] is the most useful practice of conveying cutting fluid to the interface of tool and workpiece. Nevertheless, in MQL system, a jet of cutting fluid is utilized that makes it expensive; additionally, there are some difficulties concerned with the reaching ability of the lubricant in the machining zone. Another approach known as mist lubrication technique has been verified to be an improved option where a fusion of lubricant and air is utilized on the machining zone at a high flow rate (approx. $30 \mathrm{ml} / \mathrm{h}$ ) and pressure (2-6 bar) [12-14].

MQL technology promotes evaporative, and convective heat transfer thus produces effective cooling as compared to wet cooling. Besides that, Varadarajan et al. [15] observed that the high-velocity fluid droplets penetrated the vapor blanket, and reached into tool-work interfaces-it helps to provide a better heat transfer than wet lubrication. In actual, the oil droplets reduce friction between tool and chip, where the compressed air removes metal chips from the machining zone. In another study, Astakhov [16] revealed that due to low penetrability, the aerosols did not provide boundary lubrication on the tool-workpiece interfaces. Besides that, the cooling action is also negligible because of small droplet evaporation. However, the MQL technology promotes Rebinder effect, thus the hardness and ductility of the workpiece were reduced, and a molecular film was generated on the machined zone. These justifications were in line with the observations of Varadarajan et al. [15], and Khan et al. [17]. They observed that the penetrated oil particles adhered to the machined surface, and promoted plastic flow on the back side of the chip. Hence, the machinability was tremendously improved with MQL technology.

MQL parameters also put a vital effect on machining performances. Like as, the nozzle position largely affects the penetration ability of cutting fluids into the machining zone. Attanasio et al. [18] found that as the nozzle was projected on the rake face of the cutting tool, no trace of cutting fluid was found on the machining zone, whereas a better penetration of cutting fluid was observed when the nozzle was projected on the flank faces of the tool. The idea of nozzle orientation angle was found from the study of Obikawa et al. [19]. The group of researchers found that the nozzle orientation of $45^{\circ}$ on both horizontal and vertical plane was the best choice for reducing the friction between tool and work.

Furthermore, the air pressure also had a noticeable effect on tool life, and surface finish. To check the influence of air pressure on cutting performances, Kamata and Obikawa [20] performed a cutting operation wherein the air pressure was varied from 0.4 to $0.6 \mathrm{MPa}$. The researchers found that increased air pressure value reduced the tool life and became the same as dry machining. However, the surface finish in MQL condition was better than the dry environment. In addition, the quantity of cutting fluids also affected the machining responses. From the study of Kamata and Obikawa [20], it was observed that an increment in cutting fluid quantity (from 16.8 to $31.8 \mathrm{ml} / \mathrm{h}$ ) resulted in a better tool life. However, the surface finish was not affected by fluid quantity.

The variant of MQL, titled as minimum quantity cooling lubrication (MQCL), is notable for simultaneous facilitation of cooling in addition to the lubrication at the faying surfaces. Typically, oil is used for MQL (as lubrication is a priority), and the emulsion is used as a medium for MQCL (cooling is equally important). The differences are hardly appreciated by the users, and thereby the MQL and MQCL are alternatively used. For instance, Maruda et al. [21] employed the MQCL technology to attain benefits in respect of tool wear and chip evolution, whereas Mia et al. [22] used nine times more water than oil and claimed to use the MQCL strategy in the machining of hardened steel. An 


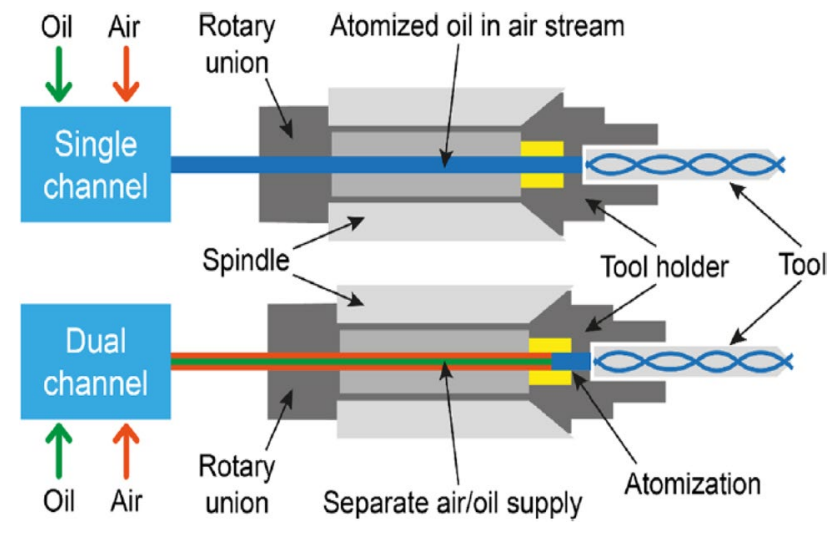

Fig. 1 MQL internal delivery system [24]

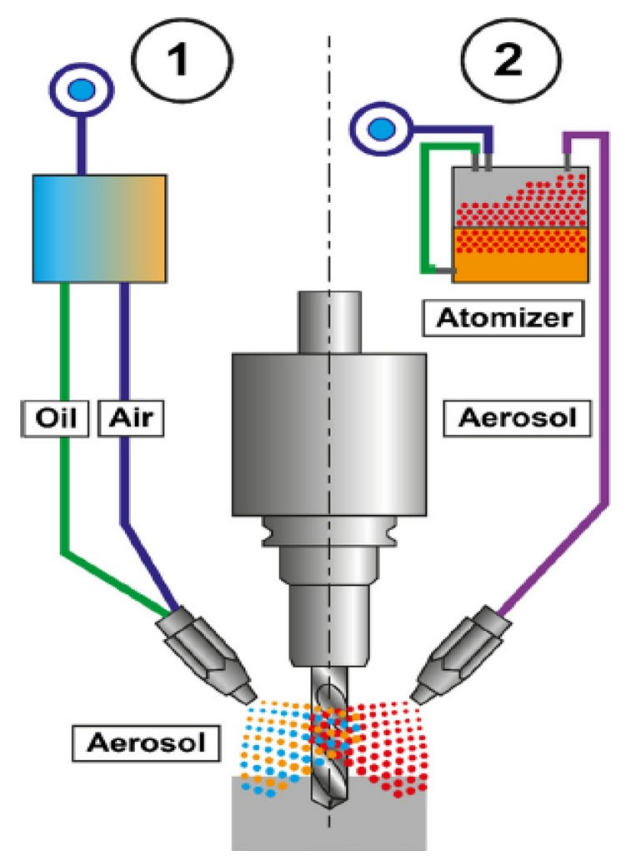

Fig. 2 MQL external delivery system: 1. Ejector nozzle, 2. Conventional nozzle [16] and Dang [23] implemented cold mist cooling system in machining of Ti alloy with proper simulation.

Generally, two different categories of the delivery system were used in MQL technology viz. internal and external delivery. In an internal delivery system, the air and lubricant were mixed up inside the nozzle and sprayed to the machining zone through a specially fabricated single/dual channels [24] (Fig. 1). On the other side, in an external delivery system, an atomizer is used to prepare the aerosol and deliver externally to the machining zone design and evaluation of an atomization-based cutting fluid spray system in turning [25]. Here also two types of nozzles are used namely ejector and conventional nozzle [16] (Fig. 2). About a year ago, Mia et al. (2017) modified the traditional technology of MQL, where the pulses of the MQL system were controlled by time. The outcomes of this study refer to the state-of-art of modern days MQL technique. The effect of time controlled MQL on surface roughness was demonstrated in Fig. 3 [26].

\subsection{Significance of MQL in Machining Domain}

A large number of research papers are available in the literature to survey the effects of MQL technology on cutting performances. Recently, Pervaiz et al. [27] showed the critical analysis of MQL in Ti alloy machining. Then, MQL showed better performance for the machining of stainless steel [28]. For cutting force, experimental outcomes demonstrated that MQL technology significantly minimizes the components of cutting force as compared to the wet and dry cooling condition [29]. In addition, the cutting forces decreased with an increment in MQL flow rate within a specified range. Beyond this limit, the decremented trend was no longer obvious [30].

As compared to the dry condition, MQL can effectively reduce the cutting temperature and thus improved the toolchip interaction and can maintain the sharpness of cutting tool [31]. However, when compared with the flooded condition, the cooling effect produced by the MQL system was not
Fig. 3 Effect of time controlled MQL on surface roughness [26]

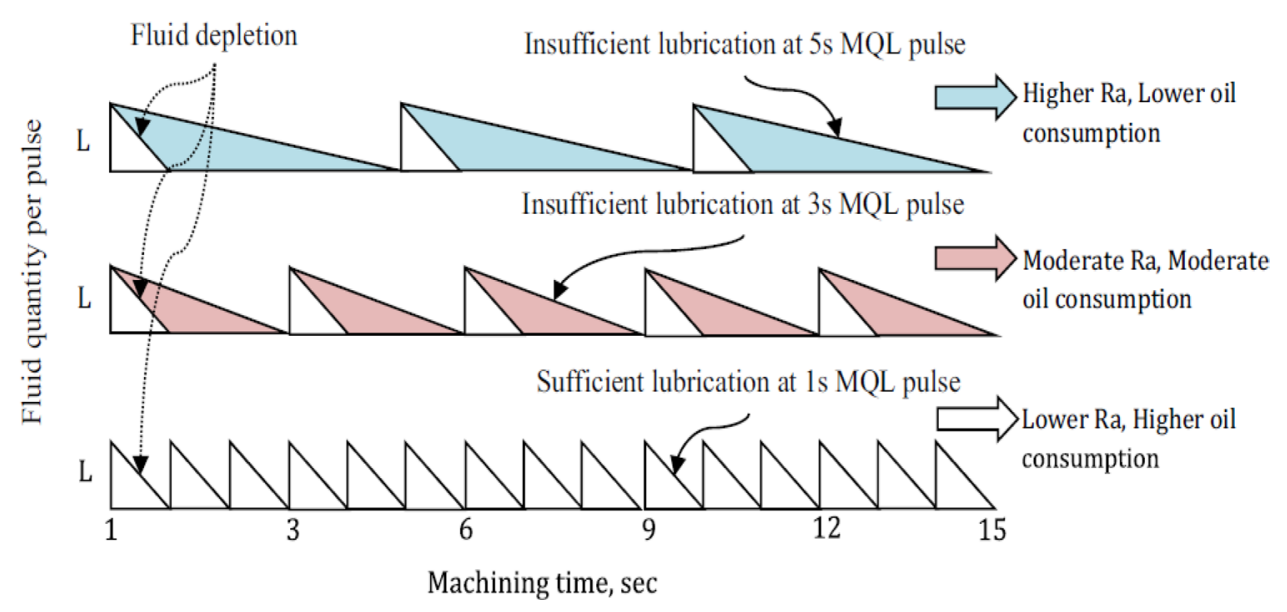

Springer $<$ 与马Е 
as good as conventional flooded technology [32]. From the perspective of cost and energy consumption, MQL stands superior too [33].

As for surface roughness, MQL was very much effective to reduce it, and the surface roughness value produced by MQL was comparable with flooded technique but far better than dry machining condition [29]. Literature also depicted that MQL technology was very much capable of reducing tool wear and improving dimensional accuracy [34]. A few years ago, Upadhyay et al. [35] crafted a fishbone diagram (Fig. 4) which illustrates the probable machining parameters and MQL conditions affecting the outcomes of MQL assisted machining operation. In this context, Maruda et al. [36] observed that MQL parameters viz. volumetric air flow and distance of nozzle had a great impact on droplet size and wetting area. Indeed, with the increment in nozzle distance and volumetric air flow, a decremented trend was observed on both the droplet diameter and wetting area (Fig. 5).

\subsection{MQL and Sustainability}

With the growth of industries, toxic and dangerous substances are increasing rapidly and affecting not only ecosystem but also human health. Thus, the concepts like green, clean and sustainable manufacturing have become important in modern practices [37]. Various acts and strategies are already implemented by the administration to make a hazard-free manufacturing environment [38]. However, the manufacturing industries have to develop a new framework to achieve sustainability goals. The proper way to improve sustainability performances is the reduction of energy consumption, recycling the industrial wastes, efficient uses of industrial resources, improvement in lubrication technology and prudent uses of natural resources [39]. In compliance with the regulatory requirements of OSHA, NIOSH, and EPA, the researchers are encouraged to innovate alternative lubrication technology for minimizing the utilization of harmful fluids in metal cutting. Consequently, the MQL comes out as a proper substitute for conventional lubrication, where MQL technology largely avoids the problem of mist generation typically encountered in flood lubrication. Many previously published works already appreciated the concept of MQL in the metal cutting domain. Nonetheless, there is a lack of implementation practice with MQL in industries. Though industries are striving to get sustainability goals through improvements in production practices (Fig. 6) [40], more cooperative efforts are required to minimize the gap between technology policy-making and execution.

Due to the great strength and rigidity of engineering alloys, the machinability of these alloys has to turn out to be an extremely significant subject for discovery. Due to which, researchers have accounted for several research papers on MQL assisted machining. Nevertheless, the key potency of the present study lies in the pictorial and tabular demonstration of the research work being carried out by various researchers. Based on the previous literature a unique B.D.P.F analysis of the MQL assisted machining strategies have been mapped in Fig. 7, and this reveals the contextual importance and opportunities of MQL mechanism in machining domain.

\section{Objectives and Methodology}

The objectives of this research article are summarized as follows:

- Collection of research articles in the area of interest.

- Identification of the particular areas where the MQL technique has been effectively applied.

- Report the benefits of vegetable oils, nanofluids, and nanoplatelets in different MQL operation.

- Sustainability evolution of MQL assisted machining technology.

- Furthermore, the authors tried to report the present challenges and future scope of MQL strategy.

Denyer and Tranfield [41] revealed that a logical review should be replicable, exclusive, aggregative and algorithmic.
Fig. 4 Fishbone structure showing MQL assisted machining parameters and condition [35]

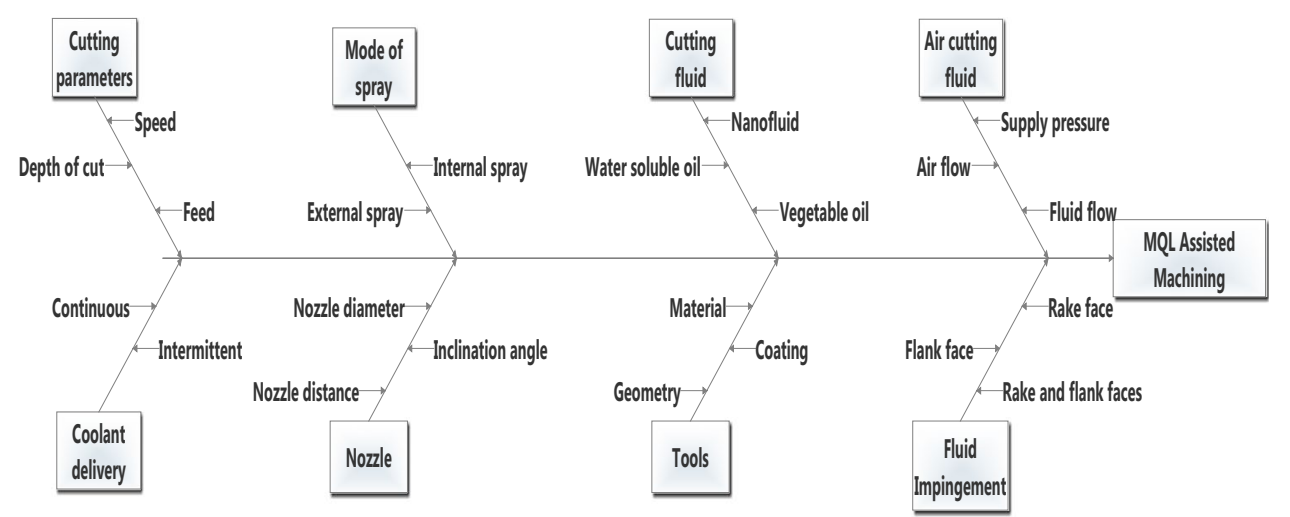


Fig. 5 Microscopic view of droplets with variable volumetric air flow and the nozzle distance [36]

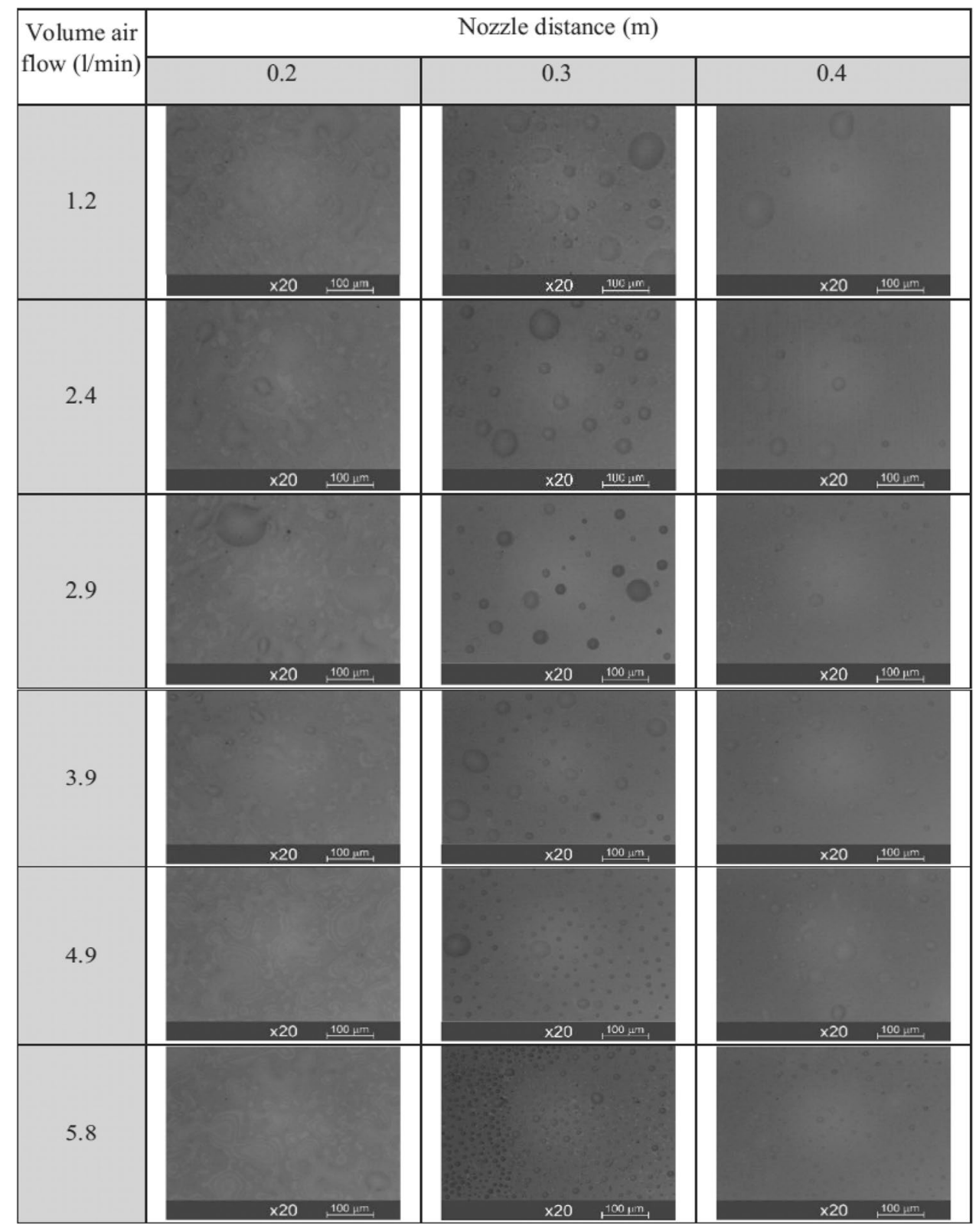

According to their statement following steps are adopted for conducting a review of the previous literature on MQL:

- Formulation of the question, which defines the focus of the review process.

- Collection of the maximum numbers of literature in the domain of interest.

- Explore the evolution of the previous literature with time.

- Analysis and synthesis of the past literature to identify the advantages and drawbacks of MQL technology.

- The collected information from the above steps can then be utilized in conclusion.

Owing to the intensive benefits derived from the usage of vegetable oils and nanofluids in MQL system, the number of MQL related research papers has grown-up over the last few years. Therefore, an effort has been made to identify all the relevant documents, which showed the use of ecofriendly cutting fluids in MQL machining. To prepare this manuscript, a detailed review of the literature has been carried out in the domain of MQL machining. Typically, the literature reviews are carried out based on employing one of three widely popular databases, which include Scopus, Web of science and Science direct. The main strings utilized in literature search included, "performance of vegetable oils in MQL assisted machining (VMQL)", and "performance of nanofluids in MQL assisted machining (NMQL)." All the research documents published from the beginning of the MQL system until December 2018 have been considered in the initial search. After the extensive screening of 
Fig. 6 Progression of sustainable manufacturing [40]

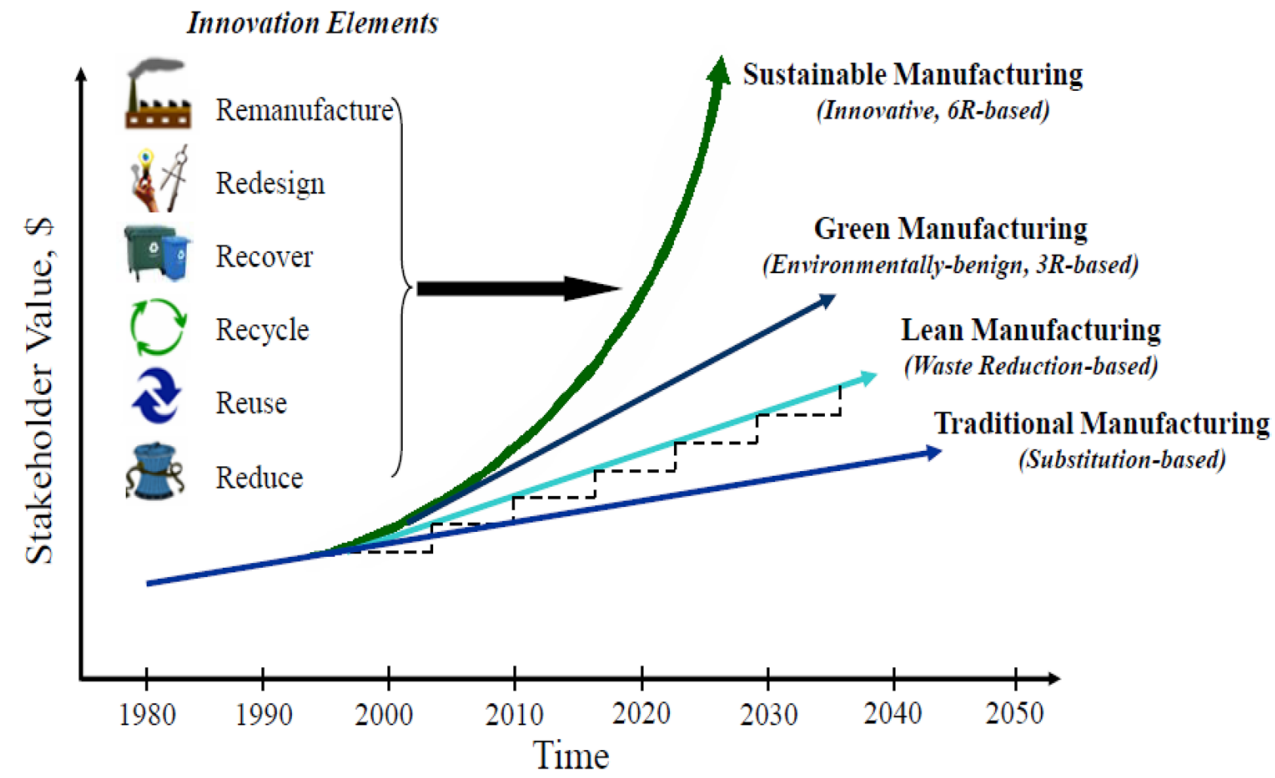

Fig. 7 B.D.P.F analysis of the MQL strategies

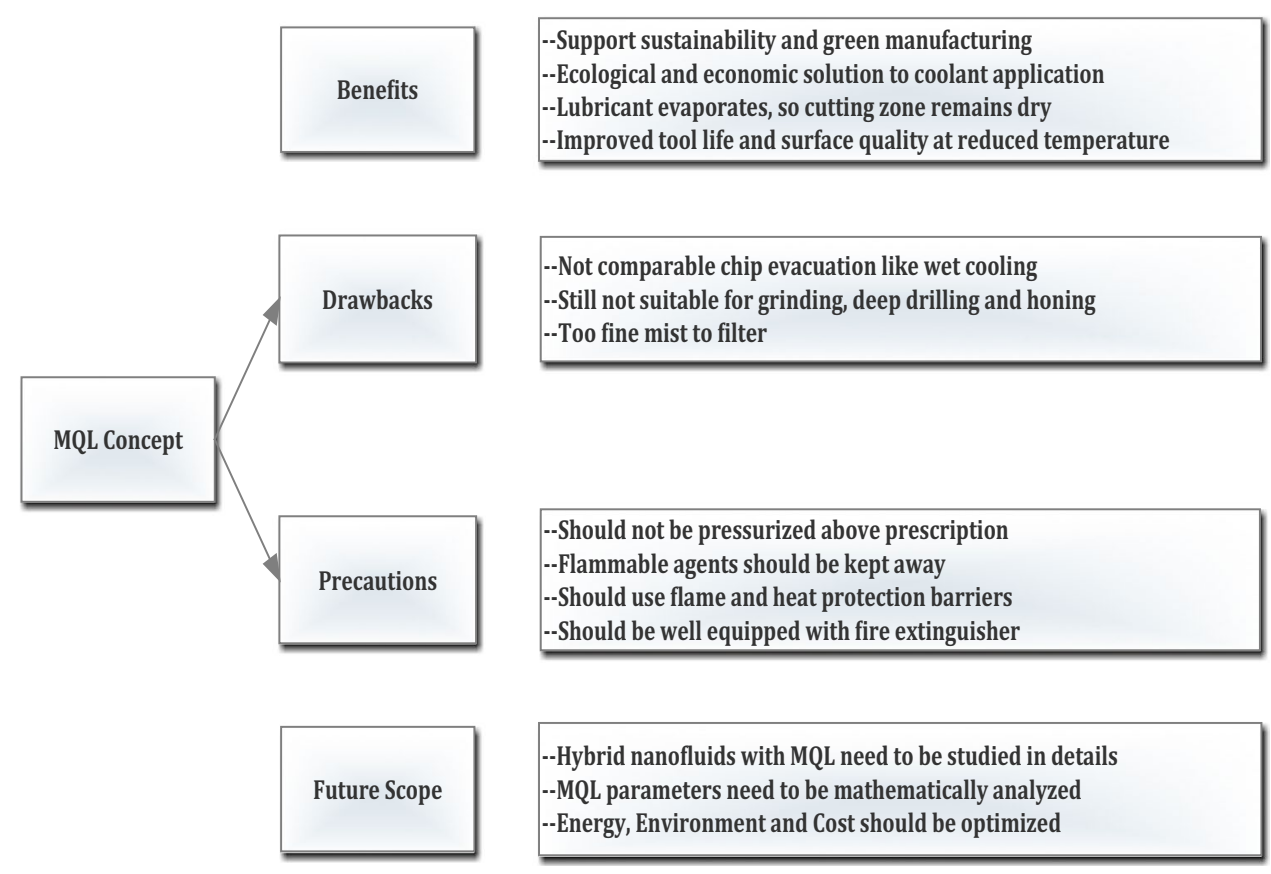

collected database from Scopus, Web of science and Science direct, we have found 615 research documents, which contain reasonable evidence of the research on VMQL and NMQL (Fig. 8). The research evidence in these documents is considered for further review.

Due to the current attention to the ecological and environmental safety, the applications of eco-friendly lubricants in the machining have perceived great attention. A critical look at literature indicates that vegetable oils and nanofluids are extensively utilized in the machining domain, but very few efforts have been made during the machining of heat resistive alloys or superalloys. Therefore it's a necessity to focus more on the appliances of eco-friendly lubricants in the machining of superalloys.

\section{Vegetable Oil Based MQL}

\subsection{Performance of Vegetable Oils in MQL Assisted Machining}

The appliance of conventional fluids has originated ecological and health difficulties. Therefore, numerous researchers decided to reduce the utilization of conventional lubricants. 

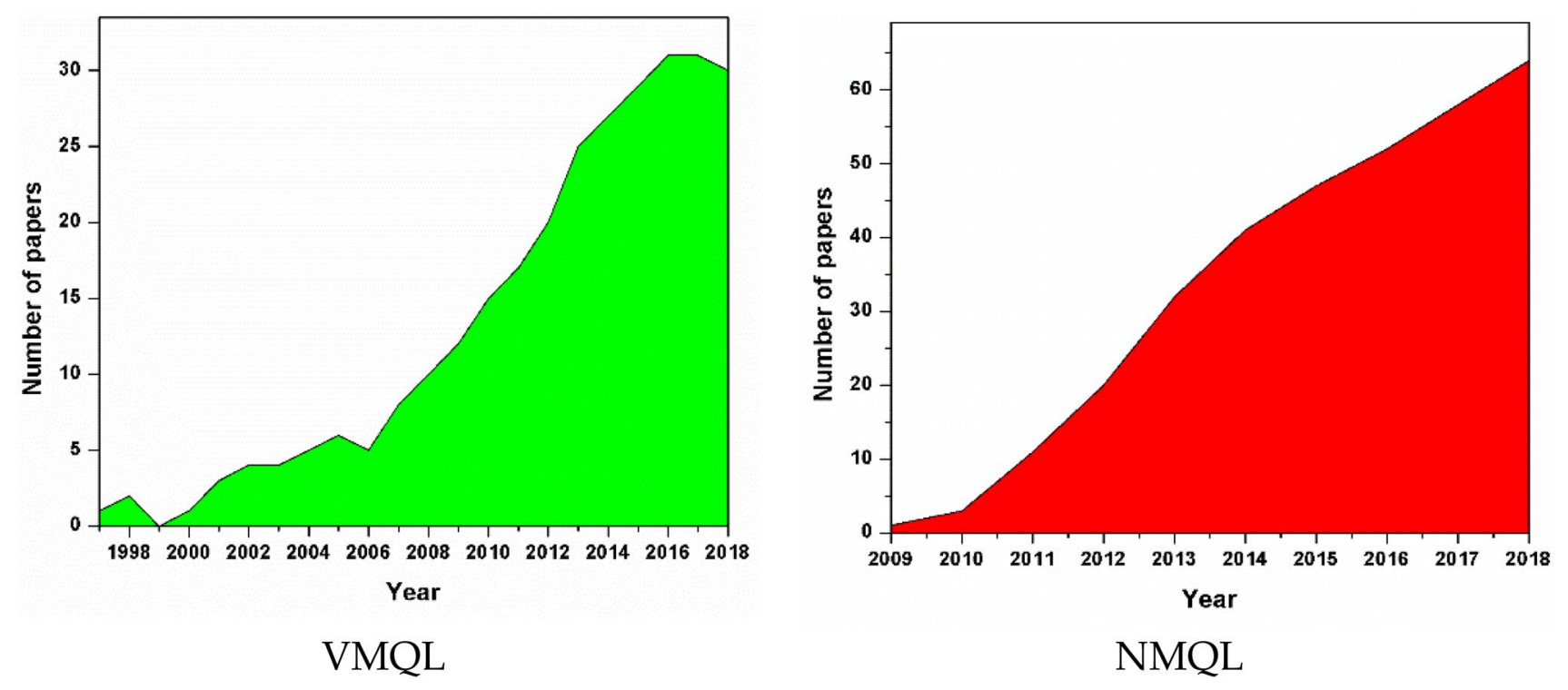

Fig. 8 No. of articles published per year a. VMQL, b. NMQL

Conversely, the machining in the dry condition is the foremost accepted substitute method to reduce the utilization of cutting lubricants. However, in dry machining, the additional friction and adhesion take place between workpiece and tool interface. Simultaneously, both workpiece and tool realize advanced thermal load and results in high abrasion, diffusion as well as oxidation. In addition, no use of cutting fluids is counter-effective in the cleaning of chips from the machining zone, and it may cause wear and tear [42, 43]. In the recent past, the solid lubricants were also utilized by few researchers for lubrication and cooling purposes [44-46]. Nonetheless, most of the researchers redirected their research work on the eco-friendly MQL technique as it significantly reduces the employment of coolant and maximizes environmental protection. For instance, Belluco and De Chiffre [47] examined the performances of five vegetable oils in the drilling of AISI 316 L. During experimentation, the chip formation, tool life, and cutting forces were considered as performance parameters. The result of this study depicted that the tool life can be increased up to $177 \%$ using vegetable oil as a lubricant. Sen et al. [48] showed the benefits of applying MQL with vegetable oil, and the advanced modeling technique to establish a beneficial manufacturing system. Ojolo et al. [49] performed an experimental work to find out the influences of vegetable oil viz. groundnut oil, palm oil, kernel oil, shear butter oil and coconut oil on cutting forces during machining of mild steel, copper, and aluminium. Experimental outcomes demonstrated that the effect of vegetable oil on turning was positive. However, the cutting force was dependent on the material to be machined. In conclusion, the authors revealed that the palm kernel oil and groundnut oil was the best choice for minimizing cutting force. Khan et al. [17] performed an experiment using vegetable oil as an MQL base fluid. The turning operation was executed on AISI 9310 material using uncoated carbide tool. During machining, researchers calculated chip formation mode, surface roughness, tool wear and cutting temperature. Furthermore, the outcomes were compared with dry and wet machining environment. In conclusion, authors revealed that cutting speed and feed rate increased the cutting temperature, drop in cutting temperature did not change the chip morphology, and MQL assisted machining demonstrated much better machining behavior as compared to dry and wet machining.

About a decade ago, Xavior and Adithan [50] experimentally demonstrated the effects of vegetable oil-based lubricants on surface morphology and tool wear. The cutting operation was performed on AISI 304 steel using a carbide tool. Coconut oil, emulsion and net cutting oil-immiscible with water was considered as cutting fluid. The outcomes of this study signified that coconut oil had a significant impact on the machining performances, whereas soluble oil had very minimal impact on surface roughness and tool wear. Kuram et al. [51] executed a drilling operation on AISI 304 steel, where HSS-E was considered as tool material. During the experiment, the authors identified the influences of cutting fluids on surface roughness and thrust force. In results, they manifested that at $720 \mathrm{rpm}$ spindle speed, commercial oil gave minimum machining responses. Mia et al. [52] adopted olive oil as a green biodegradable coolant in turning of hardened steel as the medium of MQL. They have assessed the performance with respect to the surface quality and temperature of the cutting zone. After comparing olive oil used MQL with other coolant application models, 
they concluded that MQL was the best mode for sustainable machining system. A few years ago, Wang et al. [53] calculated the lubricating properties of various vegetable oils in grinding of GH4169. Depending upon the experimental outcomes, the rank has been established as follows: maize oil $<$ rapeseed oil $<$ soybean oil $<$ sunflower oil $<$ peanut oil $<$ palm oil $<$ castor oil. The lubrication property of these vegetable oils was mainly evaluated in terms of grinding force, specific grinding energy, friction coefficient, grinding ratio, and surface morphology. Figure 9 [53] shows the morphology of grinded surfaces under flood, paraffin oil, and different vegetable oil based lubri-cooling conditions and the summary of the above-reviewed literature on VMQL is shown in Table 1.

\subsection{Lubrication Mechanisms Using Vegetable oils in Machining}

Various researchers stated that the vegetable oil-MQL synergy was better than the conventional lubrication system. The reasons for these findings are stated below:
- The main component of vegetable oil is fatty acid and triglyceride. Due to these compounds, so many polar groups like $-\mathrm{COOH}$ and -COOR are present in the molecules of vegetable oils. Figure 10 presents a typical polar molecule of vegetable oil. From the literature of Debnath et al. [54] it is observed that these polar groups are responsible for the exceptional lubrication property of vegetable oils. Actually, these polar groups act like a tiny magnet and formed a molecular film (Fig. 11) on the surface of the workpiece material and reduce friction and wear.

- Wang and Zhang [55] found that at $100^{\circ} \mathrm{C}$ (approx.) temperature, polar molecules present in the vegetable oil can react with the workpiece (metal) and produce a metallic soap film, which is responsible for good lubrication property of vegetable oil.

- The fatty acid chain of vegetable oil is composed of a huge amount of nonpolar methyl groups. Thus a dispersion force (London dispersion force) is acting between the molecules (Fig. 12). Consequently, the instantaneous dipole of the molecule induces neigh-
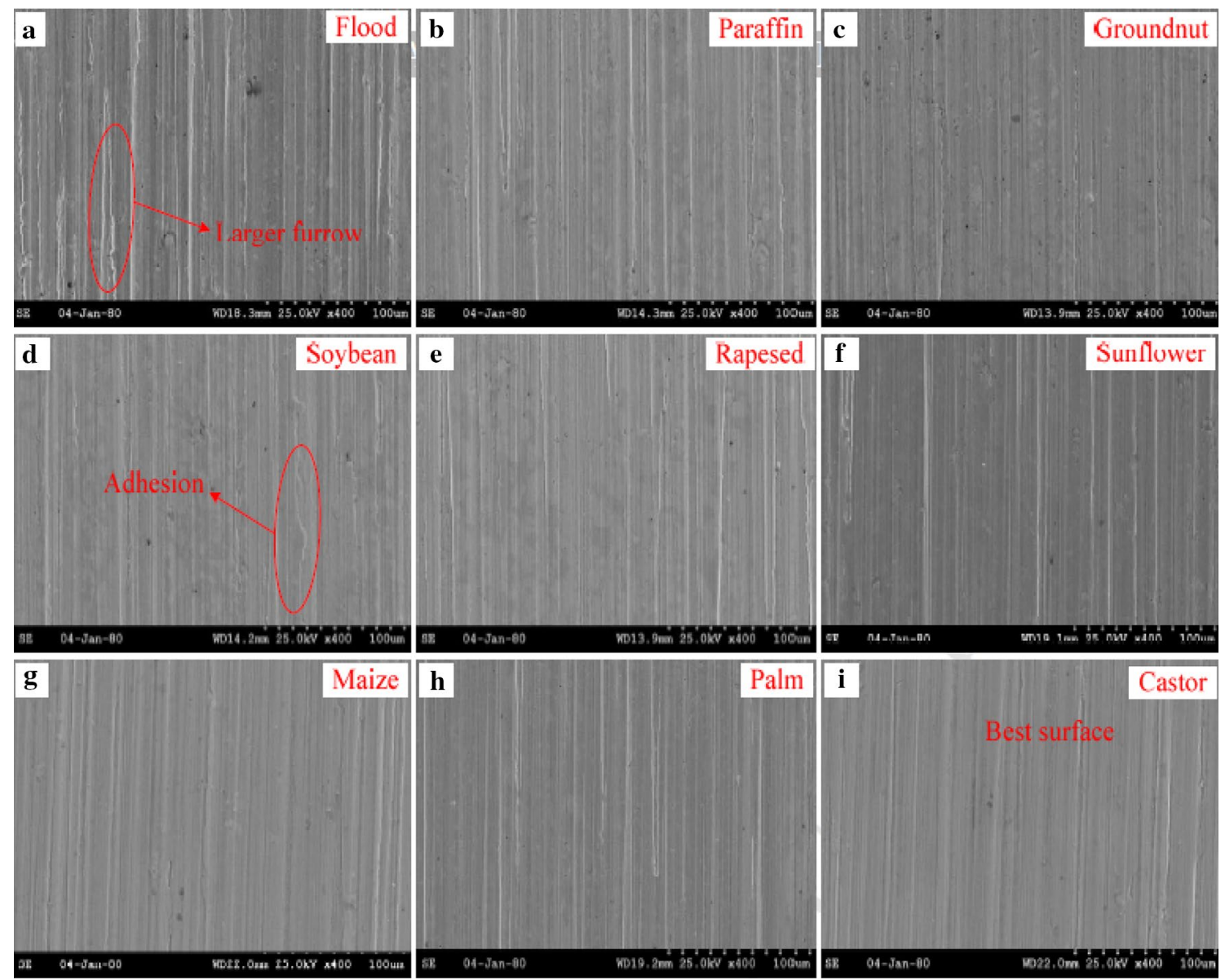

Fig. 9 Morphology of the grinded surfaces under flood, paraffin and different vegetable oil condition [53] 
Table 1 Summary of the VMQL assisted machining processes

\begin{tabular}{|c|c|c|c|c|}
\hline Authors & $\mathrm{W} / \mathrm{P}$ materials & Cutting fluid & Operation & Machining parameters \\
\hline Belluco and De Chiffre (2004) [47] & $\begin{array}{l}\text { AISI 316L } \\
\text { austenitic } \\
\text { stainless } \\
\text { steel }\end{array}$ & Commercial oil, formulated oil & Drilling & $\begin{array}{l}\text { Cutting speed }=25 \mathrm{~m} / \mathrm{min}, \\
\text { feed }=0.1 \mathrm{~mm} / \mathrm{rev}, \text { nozzle dis- } \\
\text { tance }=10 \mathrm{~mm} \text {, inclination } \\
\text { angle }=45^{\circ}\end{array}$ \\
\hline Ojolo et al. (2008) [49] & $\begin{array}{l}\text { Mild steel, } \\
\text { aluminium } \\
\text { alloy, copper } \\
\text { alloy }\end{array}$ & $\begin{array}{l}\text { Groundnut oil, coconut oil, palm } \\
\text { kernel oil, shear butter oil }\end{array}$ & Turning & $\begin{array}{l}\text { Cutting speed }=6.25,8.25,11.25 \text {, } \\
13.75 \mathrm{~m} / \mathrm{min}, \text { feed }=0.10,0.15, \\
0.20 \mathrm{~mm} / \mathrm{rev} \text {, depth of cut }=1.0,1.5 \text {, } \\
2.0,2.5 \mathrm{~mm}\end{array}$ \\
\hline Khan et al. (2009) [17] & AISI 9310 & Vegetable oil & Turning & $\begin{array}{l}\text { Cutting speed }=223,246,348 \text { and } \\
483 \mathrm{~m} / \mathrm{min}, \text { feed }=0.10,0.13 \text {, } \\
0.16 \text { and } 0.18 \mathrm{~mm} / \mathrm{rev} \text {, depth of } \\
\text { cut }=1.0 \mathrm{~mm} \text {, air pressure }=6 \mathrm{bar} \text {, } \\
\text { flow rate }=100 \mathrm{ml} / \mathrm{h}\end{array}$ \\
\hline Xavior and Adithan (2009) [50] & AISI 304 & $\begin{array}{l}\text { Coconut oil, soluble oil, straight cut- } \\
\text { ting oil }\end{array}$ & Turning & $\begin{array}{l}\text { Cutting speed }=38.95,61.35,97.38 \mathrm{~m} / \\
\text { min, feed }=0.2,0.25,0.28 \mathrm{~mm} / \mathrm{rev} \\
\text { depth of cut }=0.5,1.0,1.2 \mathrm{~mm}\end{array}$ \\
\hline Kuram et al. (2010) [51] & AISI 304 & $\begin{array}{l}\text { Sunflower oil and two commercial } \\
\text { types of oil }\end{array}$ & Drilling & $\begin{array}{l}\text { First experiment: cutting speed }=520 \text {, } \\
620,720 \mathrm{rpm}, \text { feed }=0.12 \mathrm{~mm} / \mathrm{rev} \text {, } \\
\text { depth of cut }=21 \mathrm{~mm} . \\
\text { Second experiment: cutting } \\
\text { speed }=620 \mathrm{rpm}, \text { feed }=0.08,0.12 \text {, } \\
0.16 \mathrm{~mm} / \mathrm{rev}, \text { depth of cut }=21 \mathrm{~mm} \text {. }\end{array}$ \\
\hline Wang et al. (2016) [53] & GH 4169 & $\begin{array}{l}\text { Seven types of vegetable oil and } \\
\text { parafin oil }\end{array}$ & Grinding & $\begin{array}{l}\text { Work piece speed }=30 \mathrm{~m} / \mathrm{s}, \text { wheel } \\
\text { speed }=3000 \mathrm{~mm} / \mathrm{min}, \mathrm{a}_{\mathrm{p}}=10 \mu \mathrm{m}, \\
\text { MQL flow rate }=50 \mathrm{ml} / \mathrm{h}, \mathrm{MQL} \\
\text { nozzle distance }=12 \mathrm{~mm}, \mathrm{MQL} \\
\text { nozzle angle }=15^{\circ}, \mathrm{MQL} \text { gas pres- } \\
\text { sure }=6 \text { bar }\end{array}$ \\
\hline
\end{tabular}

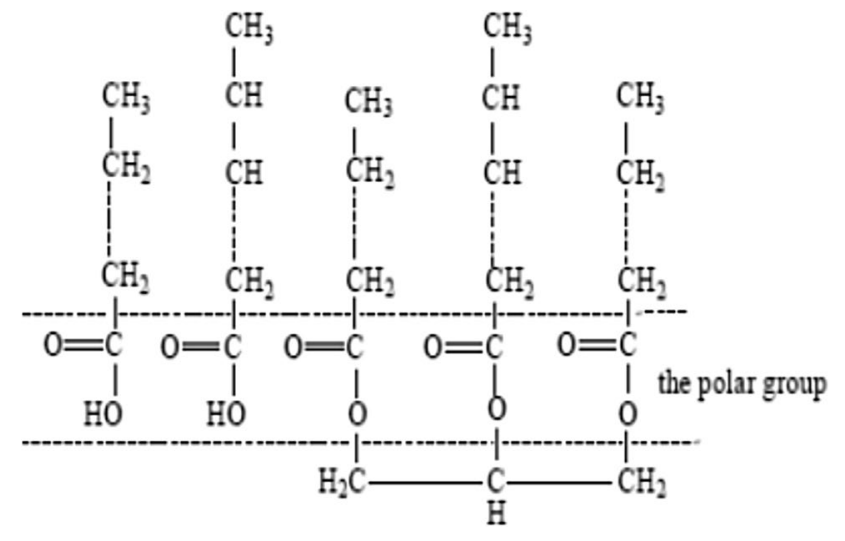

Fig. 10 A polar molecule in vegetable oil [54]

boring molecule to create dipoles. Thus two molecules are attracted to each other. As the number of carbon molecule is increased, consequently dispersion force is also increased [53].

- Generally, vegetable oil droplets have a high viscosity at a higher cutting temperature and retain for a longer time in cutting zone, which facilitates superior lubrication effect during machining [53].

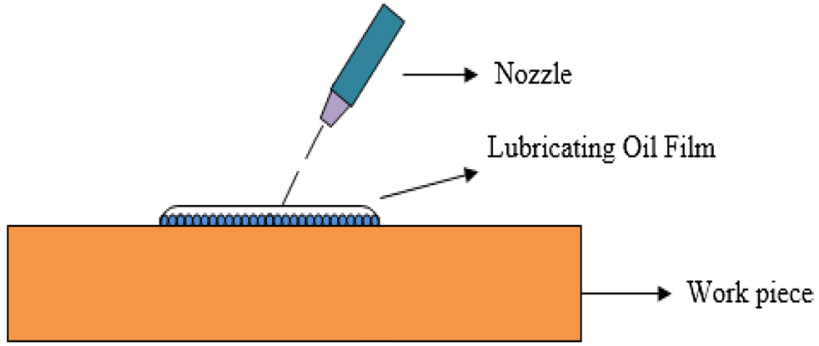

Fig. 11 Lubricating oil film

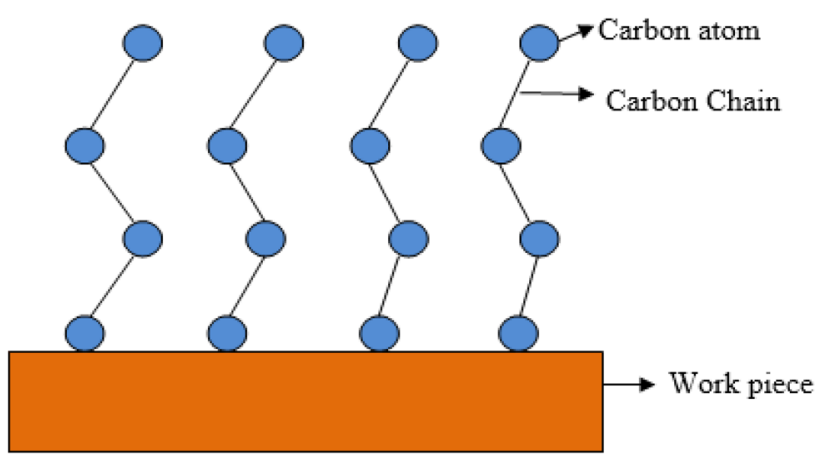

Fig. 12 London dispersion force acting between the molecules [53] 


\section{Nanofluid Based MQL}

\subsection{Synthesis, Characterization, and Thermo-Physical Properties of Nanofluid}

\subsubsection{Synthesis of Nanofluid}

Synthesis of nanofluid is the most important step in nanofluid based experimental study. Thus, a delicate preparation is required to avoid chemical changes, agglomeration, and uneven suspension of nanoparticles. Two techniques are mainly used to prepare nanofluids: One step, and Two-step method. Eastman et al. [56] proposed a One-step (physical vapor condensation technique) to prepare Cuethylene glycol nanofluids in which the congestion of nanoparticles can be reduced. This method consists of concurrently making and diffusing the particles in the base fluid. In One step method, the procedures of storage, drying, transport, and diffusion of nanoparticles are avoided, therefore assemble of nanoparticles is diminished. Moreover, the stability of fluids is also amplified. One of the advantages of this process is that it can prepare homogeneously scattered nanoparticles; in addition, the nanoparticles can be soundly suspended in the fluid.

Two-step is the most extensively employed technique for preparing nanofluids. Nanoparticles utilized in two-step method are firstly manufactured as dry powders by chemical methods. Subsequently, the nanopowder will be diffused into a base fluid/liquid in the second step by using rigorous magnetic force agitation.

This method is the most cost-effective method that has already been utilized for production levels [57].

\subsubsection{Characterization of Nanofluid}

The nanofluids are characterized by SEM, TEM, XRD, FT-IR, DLS, TGA, and Zeta potential analysis. SEM and TEM present the idea about the microstructure, and morphology of nanofluid. XRD images are analyzed to identify the crystalic structure of nanoparticles. FT-IR spectroscopy is used to study the surface chemistry of nanoparticles. DLS provides information about the disperse size, where TGA identifies the influence of heating and melting on the thermal stability of nanoparticles. Finally, Zeta potential values are calculated to determine the stability of nanoparticles in base fluid [58]. However, extensive literature revealed that different researchers applied different techniques to characterize the nanofluids, and there is no standard technique which can confirm the stability of nanofluid.

\subsubsection{Thermo-Physical Properties of Nanofluid}

Because of the small size effect of nanoparticles, the thermal conductivity of nanofluid is significantly improved [59]. In actual, considerably appreciable Brownian motion, micro-motion, and heat diffusion of nanoparticles grow the micro-convection property of nanofluid. Thus, a substantial amount of energy is transmitted between the nanoparticle and base oil, which aids to improve the thermal conductivity of nanofluid. The theoretical thermal conductivity of any nanofluid can be effectively measured using Maxwell model [60]. Recently, Sen et al. [61] observed that a higher nanoparticle deposition results in a tenderness in the experimental thermal conductivity plot, which may be related to the agglomeration of nanoparticles. In fact, the agglomeration phenomenon enhances the possibility of nanoparticle deposition in the base fluid cluster. Thus, the nano-lubricants act as an ordinary lubricant. Consequently, the heat transfer capacity of the nano-green lubricants was hampered, and the evacuation of cutting zone temperature was delayed.

The effects of the molecular interaction and irregular movements of nanoparticles in base oil define the viscosity of any nano-green lubricants [62]. As we know, the small size effect and Brownian movements of nanoparticles are responsible for the energy exchange phenomenon. Thus, the nanoparticle reinforcement effectively increases the viscosity value of the MQL base fluid. Conversely, a high viscosity value was responsible for lowering the flowability characteristics of any lubricant. In actual, as the viscosity increased, the flowability of lubricant was reduced; consequently, the lubrication time was also enhanced [63]. However, Alves et al. revealed that a high viscosity leads to strengthening the absorption film produced by nano-lubricants [64]. As already discussed that a high nanoparticle reinforcement enhances the possibility of nanoparticle agglomeration [65]. Thus, many silica nanoparticles lost their dynamic strength, and finally entrusted in the base fluid cluster. Accordingly, the viscosity and film forming capacity both were reduced.

In MQL-assisted machining, the state of Nanofluid droplets reflects the lubrication effect produced by them. Hence, the determination of the contact angle is a crucial task to check the tribological behavior of any nano-lubricant. Some previous studies demonstrated that a small contact angle reveals the superior lubricity, wherein a high contact angle value leads to weak lubrication effect [66]. Figure 13 shows the steps of synthesis, characterization, and thermo-physical properties of nanofluids.

\subsection{Performance of Nanofluid in MQL Assisted Machining}

MQL is the possible substitute to the conventional cooling technology. It also offers a choice for the manufacturer 
Fig. 13 Flowchart for synthesis, characterization and properties of nanofluid

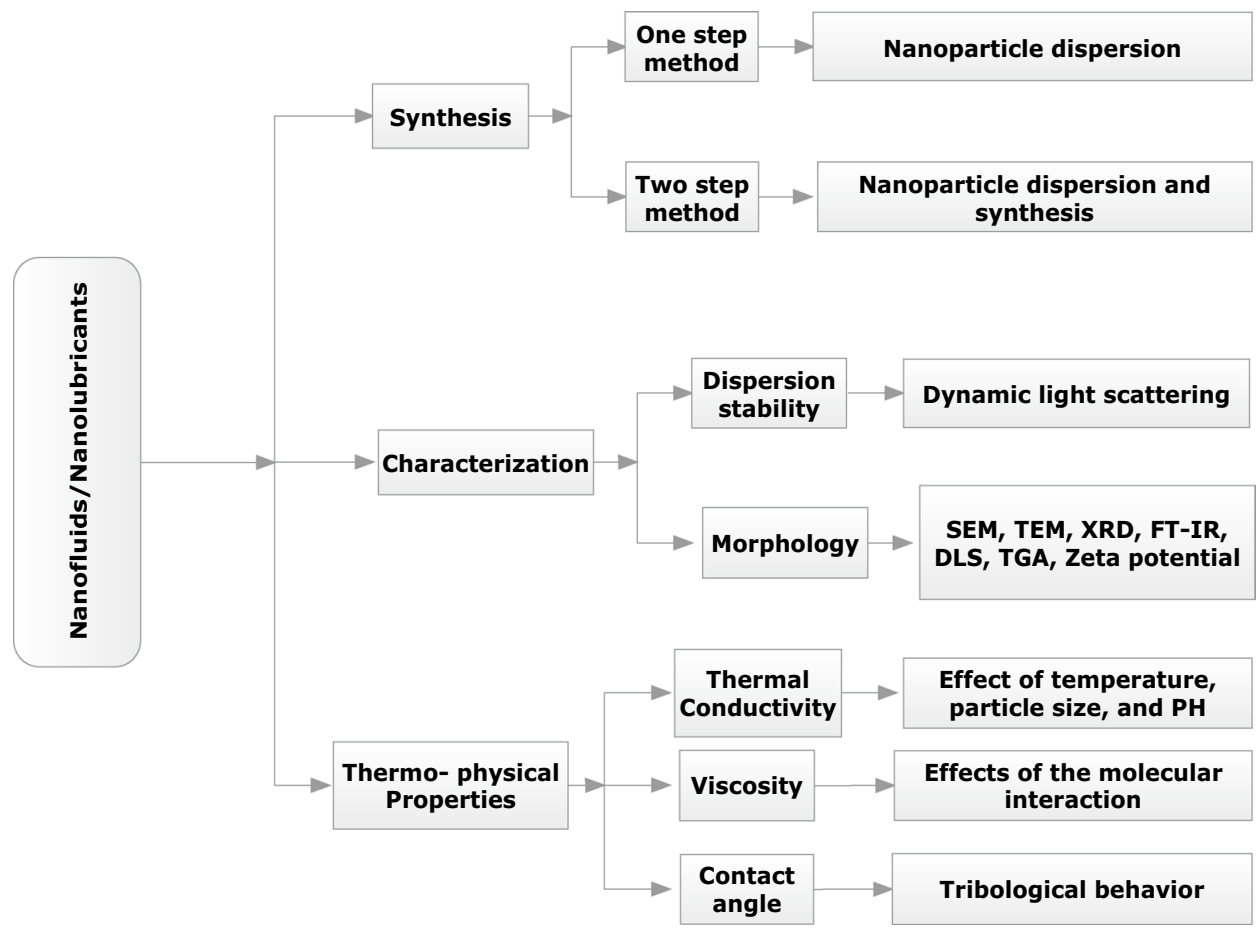

where dry machining is not applicable, particularly when machining efficacy and superior quality of the cutting area is a primary concern [31,67]. In addition, nanoparticles and nanoplatelets diffused in the MQL base fluid might be a useful technique to minimize friction throughout the machining process [68]. With the exceptional properties and minimum cost, nanoparticles and nanoplatelets are considered to be a novel, effectual choice to flood lubrication because of environmental issues [54]. Since the literature on nanofluid is extensive [69], it requires a comprehensive review to cover all the published papers. Henceforth, the present section offers a demonstrative synopsis of nanofluid-based MQL arrangements to support the objective of the study.

\subsection{1 $\mathrm{Al}_{2} \mathrm{O}_{3}$ Nanofluid}

Vasu et al. [70] performed a comparative study to determine the influences of lubricating medium viz. vegetable oil, $\mathrm{Al}_{2} \mathrm{O}_{3}$ nanofluid and dry condition on machining. The results confirmed that $\mathrm{Al}_{2} \mathrm{O}_{3}$ mixed vegetable oil effectively reduced the surface roughness, cutting force and cutting temperature as compared to other lubricating medium. Mandal et al. [71] examined the effect of volume fraction (\%) of nanoparticles in MQL assisted grinding behavior. During experimentation, AISI 52100 was used as workpiece material, and $\mathrm{Al}_{2} \mathrm{O}_{3}$ nanoparticles were used to prepared nano-fluids. $\mathrm{Al}_{2} \mathrm{O}_{3}$ nanoparticles at 1,3 and $5 \%$ with 40 and $80 \mathrm{~nm}$ dia. were mixed in deionized water. The researchers observed that a higher volume fraction of nanoparticles generated inferior machining performances as compared to lesser volume fraction. Setti et al. [72] examined the influences of $\mathrm{Al}_{2} \mathrm{O}_{3}$ and $\mathrm{CuO}$ nanoparticles in grinding of Ti-6Al-4V. The results of the experiment revealed that $\mathrm{Al}_{2} \mathrm{O}_{3}$ nanoparticles caused a minimal coefficient of friction as compared to dry, wet and $\mathrm{CuO}$ nano-fluid environment. Mao et al. [73] (2013) and Mao et al. [74] devoted their work to determine the effect of $\mathrm{Al}_{2} \mathrm{O}_{3}$ based nano-fluids on grinding of AISI 52100 . Both studies revealed that the mixing of $\mathrm{Al}_{2} \mathrm{O}_{3}$ nanoparticles in deionized water could significantly reduce the grinding forces and coefficient of friction. However, nanoparticles having a bigger diameter put an adverse effect on the surface finish. Sharma et al. [75] prepared nanofluids by adding $1 \mathrm{vol} \%$ of $\mathrm{Al}_{2} \mathrm{O}_{3}$, whereas vegetable oil and water emulsion were considered as MQL base fluid. The turning operation was performed on AISI 1040, and the prepared nanofluids were used as a lubricant. The outcomes of this experiment were comprehensively compared with conventional flood machining and found $25.5 \%, 5.27 \%$, and $28 \%$ reduction respectively in surface roughness, tool wear and cutting force. The summary of the literature on $\mathrm{Al}_{2} \mathrm{O}_{3}$ based MQL assisted machining processes are displayed in Table 2.

\subsection{2 $\mathrm{MoS}_{2}$ Nanofluid}

In a particular study, Padmini et al. [76], mixed the nano and microparticles of boric and $\mathrm{MoS}_{2}$ in sesame and coconut oil and applied these as a lubricant. The outcomes of this study demonstrated that the nano-fluids acted much superior to micro fluids in minimizing cutting temperature, cutting forces and surface roughness during machining. Zhang et al. 
Table 2 Summary of machining under $\mathrm{Al}_{2} \mathrm{O}_{3}$ based MQL

\begin{tabular}{|c|c|c|c|c|c|}
\hline \multirow[t]{2}{*}{ Authors } & \multirow[t]{2}{*}{$\mathrm{W} / \mathrm{P}$ materials } & \multirow[t]{2}{*}{ Nanoparticle used } & \multirow[t]{2}{*}{ Operation } & \multicolumn{2}{|l|}{ Critical parameters } \\
\hline & & & & Machining parameters & MQL parameters \\
\hline Vasu et al. (2011) [70] & Inconel 600 & $\mathrm{Al}_{2} \mathrm{O}_{3}$ & Turning & $\begin{array}{l}\text { Cutting speed }=40,50, \\
60 \mathrm{~m} / \mathrm{min}, \text { feed }=0.08, \\
0.12,0.16 \mathrm{~mm} / \mathrm{rev}, \text { depth } \\
\text { of } \text { cut }=0.4,0.8,1.2 \mathrm{~mm}\end{array}$ & $\begin{array}{l}\text { Air pressure }=5 \text { bar, lubri- } \\
\text { cation }=100 \mathrm{ml} / \mathrm{h}\end{array}$ \\
\hline Mandal et al. (2012) [71] & AISI 52100 & $\mathrm{Al}_{2} \mathrm{O}_{3}$ & Grinding & Not provided & Not provided \\
\hline Setti et al. (2012) [72] & Ti-6Al-4V & $\mathrm{Al}_{2} \mathrm{O}_{3}$ & Grinding & $\begin{array}{l}\text { Wheel speed }=10.89,16.34 \text {, } \\
21.79 \mathrm{~m} / \mathrm{sec}, \text { work piece } \\
\text { speed }=3,9,15 \mathrm{~mm} / \mathrm{rev}, \\
\text { depth of cut }=10,20 \\
30 \mathrm{~mm}\end{array}$ & $\begin{array}{l}\text { Flow rate }=18 \mathrm{ml} / \mathrm{h} \text {, air } \\
\text { pressure }=1.5 \mathrm{bar}\end{array}$ \\
\hline Mao et al. (2013) [73] & AISI 52100 & $\begin{array}{l}\mathrm{Al}_{2} \mathrm{O}_{3} / \text { water based nano- } \\
\text { fluid }\end{array}$ & Grinding & $\begin{array}{l}\text { Work piece speed }=0.05 \mathrm{~m} / \\
\text { sec, depth of cut }=10 \mu \mathrm{m}, \\
\text { drill dia }=200 \mathrm{~mm} \text {, wheel } \\
\text { speed }=31.4 \mathrm{~m} / \mathrm{sec}\end{array}$ & $\begin{array}{l}\text { Spraying distance }=20, \\
40,60 \mathrm{~mm}, \mathrm{MQL} \text { flow } \\
\text { rate }=60 \mathrm{ml} / \mathrm{h}\end{array}$ \\
\hline Sharma et al. (2016a) [75] & AISI 1040 & $\mathrm{Al}_{2} \mathrm{O}_{3}$ & Turning & $\begin{array}{l}\text { Cutting speed }=96.7 \mathrm{~m} / \\
\text { min, feed }=0.1 \mathrm{~mm} / \mathrm{rev} \\
\text { depth of cut }=1.0 \mathrm{~mm}\end{array}$ & $\begin{array}{c}\text { Flow rate }=50 \mathrm{ml} / \mathrm{min} \text {, air } \\
\text { pressure }=4 \mathrm{bar} \text {, nozzles } \\
\text { inclination angle }=30^{\circ}\end{array}$ \\
\hline
\end{tabular}

[77] mixed $\mathrm{MoS}_{2}$ nanoparticle in palm, soybean and rapeseed oil and applied these nano-fluids in the tool-workpiece interface during MQL assisted grinding operation. The result showed that $\mathrm{MoS}_{2}$ in soybean oil was the most preeminent condition for grinding. Padmini et al. [78] expanded the study to scrutinize the performance of $\mathrm{MoS}_{2}$ /sesame, $\mathrm{MoS}_{2} /$ coconut, and $\mathrm{MoS}_{2} /$ canola in the machining of AISI 1040. Amongst the mixture, $0.5 \% \mathrm{MoS}_{2}$ with coconut oil performed better than other lubricants and reduced the cutting forces, temperatures, tool wear, and surface roughness by $37 \%, 21 \%, 44 \%$, and $39 \%$ respectively as compared to dry machining. The summary of the literature on $\mathrm{MoS}_{2}$ based MQL assisted machining processes are displayed in Table 3.

\subsubsection{Diamond Nanofluid}

Nam and Lee [79] presented a comprehensive study on the machining of Ti alloy under the impingement of MQL using diamond nanoparticles. They claimed reduction of cutting force, and reduction of chip adhesion. Nam et al. [80] used diamond particles (dia. $30 \mathrm{~nm}$ ) in vegetable and paraffin oils distinctly. Afterward, the prepared nano-fluids were used as a lubricant while machining of Al-6061. Experimental outcomes demonstrated that both nanofluids significantly reduced the drilling torque. Nevertheless, the paraffin oil-based nano-fluid showed much better lubrication properties as compared to vegetable oil based nano-fluids. In another study, Nam et al. [81] perceived that the employment of diamond nanoparticles with larger diameter was not efficient for the drilling operation. The summary of the literature on nano-diamond based MQL assisted machining processes are displayed in Table 4.

Table 3 Summary of machining under $\mathrm{MoS}_{2}$ based MQL

\begin{tabular}{|c|c|c|c|c|c|}
\hline \multirow[t]{2}{*}{ Authors } & \multirow[t]{2}{*}{$\mathrm{W} / \mathrm{P}$ materials } & \multirow[t]{2}{*}{ Nanoparticle used } & \multirow[t]{2}{*}{ Operation } & \multicolumn{2}{|l|}{ Critical parameters } \\
\hline & & & & Machining parameters & MQL parameters \\
\hline Padmini et al. [76] & AISI 1040 & $\mathrm{H}_{3} \mathrm{BO}_{3}$ and $\mathrm{MoS}_{2}$ & Turning & $\begin{array}{l}\text { Cutting speed }=60 \mathrm{~m} / \mathrm{min}, \\
\text { feed }=0.14 \mathrm{~mm} / \mathrm{rev}, \text { depth of } \\
\text { cut }=0.5 \mathrm{~mm}\end{array}$ & Not provided \\
\hline Zhang et al. [77] & 45 Steel & $\mathrm{MoS}_{2}$ & Grinding & $\begin{array}{l}\text { Wheel speed }=60 \mathrm{~m} / \mathrm{sec}, \\
\text { feed }=3000 \mathrm{~mm} / \mathrm{min} \text {, depth of } \\
\text { cut }=10 \mu \mathrm{m}\end{array}$ & $\begin{array}{l}\text { Flow rate }=50 \mathrm{ml} / \mathrm{h}, \text { nozzle } \\
\text { distance }=12 \mathrm{~mm} \text {, nozzle } \\
\text { angle }=15^{0}, \text { gas pressure }=6 \mathrm{bar}\end{array}$ \\
\hline Padmini et al. [78] & AISI 1040 & $\mathrm{MoS}_{2}$ & Turning & $\begin{array}{l}\text { Cutting speed }=40,60,100 \mathrm{~m} / \mathrm{sec} \\
\text { feed }=0.14,0.17,0.2 \mathrm{~mm} / \mathrm{rev} \\
\text { depth of } \text { cut }=0.5 \mathrm{~mm}\end{array}$ & Flow rate $=10 \mathrm{ml} / \mathrm{min}$ \\
\hline
\end{tabular}


Table 4 Summary of machining under nano-diamond based MQL

\begin{tabular}{|c|c|c|c|c|c|}
\hline \multirow[t]{2}{*}{ Authors } & \multirow[t]{2}{*}{$\mathrm{W} / \mathrm{P}$ materials } & \multirow[t]{2}{*}{ Nanoparticle used } & \multirow[t]{2}{*}{ Operation } & \multicolumn{2}{|l|}{ Critical parameters } \\
\hline & & & & Machining parameters & MQL parameters \\
\hline Nam et al. (2011) [80] & Aluminum 6061 & Nano diamond & Micro-drilling & $\begin{array}{l}\text { Cutting speed }=60,000 \mathrm{rpm}, \text { feed }=50 \mathrm{~mm} / \\
\text { min, depth of cut }=0.4 \mathrm{~mm}\end{array}$ & Not provided \\
\hline Nam et al. (2013) [81] & Aluminum 6061 & Nano diamond & Micro-drilling & $\begin{array}{l}\text { Cutting speed }=30,000,60,000 \mathrm{rpm}, \text { feed }=10, \\
15 \mathrm{~mm} / \mathrm{min} \text {, depth of cut }=0.1,0.5 \mathrm{~mm}\end{array}$ & Not provided \\
\hline
\end{tabular}

\subsection{4 $\mathrm{SiO}_{2}$ Nanofluid}

Sarhan et al. [82] performed a milling operation while using $\mathrm{SiO}_{2}$ nano-fluid as a lubricant. The experimental findings demonstrated that $\mathrm{SiO}_{2}$ could significantly reduce cutting forces as well as specific energy consumption as compared to mineral oil. Sayuti et al. [83] examined the effects of $\mathrm{SiO}_{2}$ nano-fluids in the machining of AISI4140 steel. The result of this study revealed that surface roughness could be minimized at $30^{\circ} \mathrm{MQL}$ nozzle angle, $0.5 \% \mathrm{wt} \mathrm{SiO}_{2}$ concentration and low air pressure, where minimum tool wear could be achieved by $60^{\circ} \mathrm{MQL}$ nozzle angle, $0.5 \% \mathrm{SiO}_{2}$ concentration and 2 bar air pressure. Ooi et al. [84] performed a milling operation on Al-6061-T6 alloy and used $\mathrm{SiO} 2$ nanofluid as a lubricant. Furthermore, the researchers developed a fuzzy logic based predictive model to remove the ambiguity of the experimental data. The predictive results demonstrated 91.37-98.27\% accuracy with experimental outputs. The summary of the literature on $\mathrm{SiO}_{2}$ based MQL assisted machining processes are displayed in Table 5.

\subsubsection{CNT Nanofluid}

You and Gao [85] utilized the CNT particles for nanomachining. They suggested that CNT grinding wheels produced the best results and can be employed as cutting grains for Nano-machining. Rao et al. [86] performed an experimental study to determine the influences of CNT nanoparticles on turning operation. During the experiment, researchers varied the concentration (\%) of CNT particles in the MQL base fluid and found at 2\% CNT inclusion minimum tool wear and cutting temperature can be achieved. Prabhu and Vinayagam [87] performed an AFM analysis for grinding of AISI D3 steel material. Taguchi's morphology was considered to design and optimize the grinding inputs. Furthermore, regression analysis was performed to forecast the machining responses. The result of this particular study demonstrated that CNT nano-fluids could effectively minimize the micro-cracks as well as surface roughness as compared to dry machining condition. Sayuti et al. [88] examined the effects of $\mathrm{SiO}_{2}$ nano-fluids in the machining of AISI4140 steel. The result of this study revealed that surface roughness could be minimized at $30^{\circ} \mathrm{MQL}$ nozzle angle, $0.5 \%$ wt $\mathrm{SiO}_{2}$ concentration and low air pressure, where minimum tool wear could be achieved by $60^{\circ} \mathrm{MQL}$ nozzle angle, $0.5 \% \mathrm{SiO}_{2}$ concentration and 2 bar air pressure. The summary of the literature on CNT based MQL assisted machining processes are displayed in Table 6.

\subsubsection{Nanoplatelet}

Among different nanoparticles, the graphene nanoplatelets $(\mathrm{GnP})$ greatly caught the attention of the researchers, due to its excellent lubrication property and high thermal conductivity. Over the last decade, so many research works were published on GnP based MQL technology. For instance, Huang et al. [89] performed an experimental study and observed that GnP greatly enhances the anti-wear property

Table 5 Summary of machining under $\mathrm{SiO}_{2}$ based MQL

\begin{tabular}{|c|c|c|c|c|c|}
\hline \multirow[t]{2}{*}{ Authors } & \multirow[t]{2}{*}{$\mathrm{W} / \mathrm{P}$ materials } & \multirow{2}{*}{$\begin{array}{l}\text { Nano- } \\
\text { particle } \\
\text { used }\end{array}$} & \multirow[t]{2}{*}{ Operation } & \multicolumn{2}{|l|}{ Critical parameters } \\
\hline & & & & Machining parameters & MQL parameters \\
\hline Sarhan et al. (2012) [82] & Aluminium AA6061-T6 & $\mathrm{SiO}_{2}$ & Milling & $\begin{array}{l}\text { Cutting speed }=5000 \mathrm{~min}^{-1}, \\
\text { feed }=100 \mathrm{~mm} / \mathrm{min} \text {, depth of } \\
\text { cut }=5 \mathrm{~mm}\end{array}$ & $\begin{array}{l}\text { Nozzle angle }=45^{\circ}, \mathrm{MQL} \text { oil } \\
\text { pressure }=20 \mathrm{Mpa} \text {, delivery } \\
\text { rate }=2 \mathrm{ml} / \mathrm{min}\end{array}$ \\
\hline Sayuti et al. (2014) [83] & AISI 4140 & $\mathrm{SiO}_{2}$ & Hard turning & $\begin{array}{l}\text { Cutting speed }=120 \mathrm{~m} / \mathrm{min} \text {, } \\
\text { feed }=0.15 \mathrm{~mm} / \mathrm{rev} \text {, depth of } \\
\text { cut }=0.5 \mathrm{~mm}\end{array}$ & $\begin{array}{l}\text { Air pressure }=1-4 \text { bar, nozzle } \\
\text { orientation angle }=15-60^{\circ}\end{array}$ \\
\hline Ooi et al. (2015) [84] & AISI-6061-T6 & $\mathrm{SiO}_{2}$ & CNC milling & $\begin{array}{l}\text { Cutting speed }=5000 \mathrm{~min}^{-1}, \\
\text { feed }=100 \mathrm{~mm} / \mathrm{min} \text {, depth of } \\
\text { cut }=5 \mathrm{~mm}\end{array}$ & $\begin{array}{l}\text { Air pressure }=1-4 \text { bar, nozzle } \\
\text { orientation angle }=15-60^{\circ}\end{array}$ \\
\hline
\end{tabular}


Table 6 Summary of machining under CNT based MQL

\begin{tabular}{|c|c|c|c|c|c|}
\hline \multirow[t]{2}{*}{ Authors } & \multirow[t]{2}{*}{$\mathrm{W} / \mathrm{P}$ materials } & \multirow[t]{2}{*}{ Nanoparticle used } & \multirow[t]{2}{*}{ Operation } & \multicolumn{2}{|l|}{ Critical parameters } \\
\hline & & & & Machining parameters & MQL parameters \\
\hline Rao et al. (2011) [86] & AISI 1040 & CNT & Turning & $\begin{array}{l}\text { Cutting speed }=102 \mathrm{~m} / \\
\text { min, feed }=0.44 \mathrm{~mm} / \\
\text { rev, depth of cut }=0 . \\
5 \mathrm{~mm}\end{array}$ & Not provided \\
\hline $\begin{array}{l}\text { Prabhu and Vinayagam } \\
\text { (2012) [87] }\end{array}$ & AISI D3 tool steel & MWCNT & Grinding & $\begin{array}{l}\text { Wheel speed }=2000, \\
2500 \mathrm{rpm}, \text { feed }=1.9, \\
2.5 \mathrm{~mm} / \mathrm{min}, \text { depth of } \\
\text { cut }=0.1,0.2 \mathrm{~mm}\end{array}$ & Not provided \\
\hline Sayuti et al. (2013) [88] & AL-2017-T4 & $\begin{array}{l}\text { Carbon onion nano- } \\
\text { lubricant }\end{array}$ & CNC milling & $\begin{array}{l}\text { Cutting } \\
\text { speed }=75.408 \mathrm{~m} / \\
\text { min, feed }=100 \mathrm{~mm} / \\
\text { min, depth of } \\
\text { cut }=1.0 \mathrm{~mm}\end{array}$ & Not provided \\
\hline Wang et al. (2016) [95] & Nickel alloy (GH4169) & $\begin{array}{c}\mathrm{MoS}_{2}, \mathrm{SiO}_{2} \text {, diamond, } \\
\mathrm{CNT}, \mathrm{Al}_{2} \mathrm{O}_{3}, \mathrm{ZrO}_{2}\end{array}$ & Plane grinding & $\begin{array}{l}\text { Wheel speed }=30 \mathrm{~m} / \\
\text { sec, Work piece } \\
\text { speed }=3000 \mathrm{~mm} / \\
\text { min, depth of } \\
\text { cut }=10 \mu \mathrm{m}\end{array}$ & $\begin{array}{l}\text { MQL flow rate }=50 \mathrm{ml} / \mathrm{h} \text {, } \\
\text { MQL nozzle } \\
\text { angle }=15^{\circ}, \mathrm{MQL} \mathrm{noz-} \\
\text { zle distance }=12 \mathrm{~mm} \text {, } \\
\text { MQL gas pres- } \\
\text { sure }=6 \mathrm{Mpa}\end{array}$ \\
\hline
\end{tabular}

of paraffin oil. Marcon et al. [90] mixed up GnP in the cutting fluid and examined the influence of this mixture during micro-milling operation. The results of this study depicted that $\mathrm{GnP}$ based cutting fluid significantly reduced the cutting temperature and tool wear. In a particular study, Alberts et al. [91] observed the effectiveness of GnP in surface grinding operation. The outcomes of this study demonstrated that $\mathrm{GnP}$ based cutting fluids are very much favorable for the grinding operation of D-2 steel. Ravuri et al. [92] used GnP impregnated grinding wheel in the machining of Inconel 718 and observed a significant improvement in grinding wheel life and surface finish. In recent times, Pavan et al. [93] executed an experimental study in MQL assisted the grinding environment. The outcomes of this study depicted that $0.3 \% \mathrm{GnP}$ in the base fluid can effectively improve the surface quality of Inconel 718. Furthermore, Kwon and Drazel [94] issued a patent on XGnP based MQL technology to display the effectiveness of GnP. The outcomes of this study depicted that $\mathrm{GnP}$ based cutting fluids were very much effectual in minimizing chipping and maximizing tool life.

A few years ago, Wang et al. [95] investigated that $\mathrm{Al}_{2} \mathrm{O}_{3}$ nanoparticles demonstrated superior lubricating property when compared to other nanoparticles. The researchers performed an experiment on GH4169, where palm oil was used as MQL base fluid. According to the acquired results, the rank has been enlisted as follows: $\mathrm{ZrO}_{2}<\mathrm{CNT}<\mathrm{ND}<\mathrm{MoS}_{2}<\mathrm{SiO}_{2}<\mathrm{Al}_{2} \mathrm{O}_{3}$. Figure 14 [95] shows the morphology of grinded surfaces under different nanofluid conditions. In addition, some researchers like Beyth et al. [96]; Marsalek et al. [97]; Salehi et al. [98]; Tseng et al. [99] have confirmed that nanoparticles have antimicrobial, antibacterial, non-toxic and deodorizing, properties which support the concept of green manufacturing. The summary of the literature on Nanoplatele based MQL assisted machining processes are displayed in Table 7.

\subsection{Lubrication Mechanisms Using Nanofluid in Machining}

Due to the existence of vacant bonds, nanoparticles are unstable, unsaturated and can attach easily to other atoms. Conversely, nanoparticles can combine with the polar atoms of vegetable oil and produce high surface energy. The surface effect of the nanoparticle is shown in Fig. 15. Furthermore, nanoparticle shows the following important characteristics when dispersed in the cutting zone Understanding the role of nanoparticles in nano-oil lubrication [100]:

- The incorporation of different nanoparticles in the MQL fluid considerably diminished friction as well as wear rate and thus advance the tribological assets of the lubricants.

- The nanoparticles have a propensity to build up a surface protecting film.

- The circularly shaped particles were revolved between tool-workpiece interfaces and converted the sliding into rolling-sliding friction.

- The nanoparticles demonstrated mending effect in machining endeavor.

- The high contact pressure reduced the compressive stress concentrations. Thus nanoparticles uniformly endure the 
Fig. 14 Morphology of the grinded surfaces under different nanofluid condition [95]
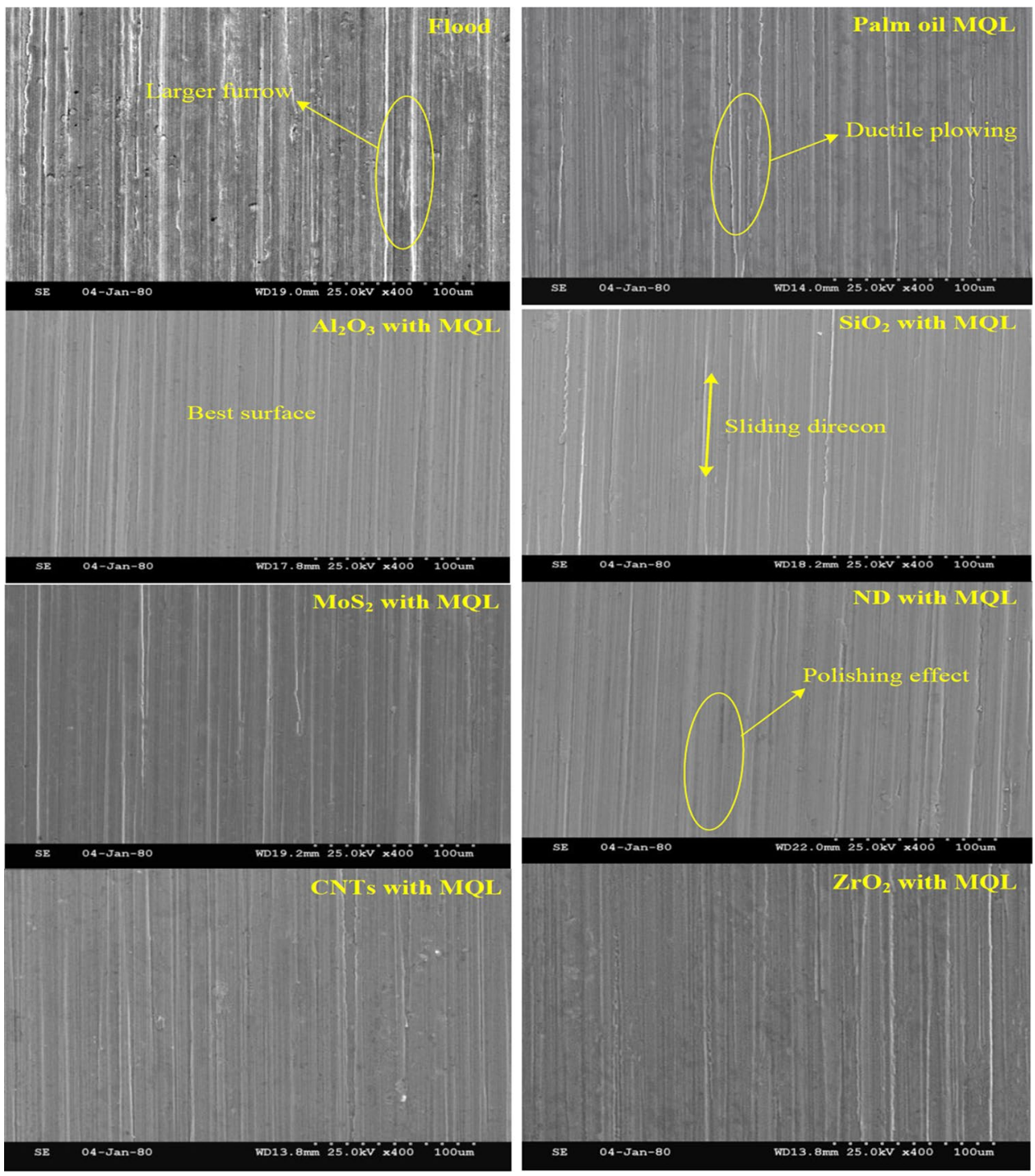

Table 7 Summary of machining under nanoplatelet based MQL

\begin{tabular}{|c|c|c|c|c|c|}
\hline \multirow[t]{2}{*}{ Authors } & \multirow[t]{2}{*}{$\mathrm{W} / \mathrm{P}$ materials } & \multirow[t]{2}{*}{ Nanoparticle used } & \multirow[t]{2}{*}{ Operation } & \multicolumn{2}{|l|}{ Critical parameters } \\
\hline & & & & Machining parameters & MQL parameters \\
\hline Huang et al. (2006) [89] & Steel ball & Graphene nanoplatelet & Not provided & Not provided & Not provided \\
\hline Marcon et al. (2010) [90] & H13 steel & Graphene nanoplatelet & Micro-milling & $\begin{array}{l}\text { Spindle } \\
\text { speed }=60,000 \mathrm{rpm} \text {, axial } \\
\text { depth of cut }=30 \mu \mathrm{m}\end{array}$ & $\begin{array}{l}\text { Nozzle diameter }=0.8 \mathrm{~mm} \text {, } \\
\text { MQL flow rate }=15, \\
100 \mathrm{ml} / \mathrm{min}\end{array}$ \\
\hline Alberts et al. (2009) [91] & D-2 tool steel & Graphene nanoplatelet & Surface grinding & $\begin{array}{l}\text { Wheel peripheral } \\
\text { speed }=25 \mathrm{~m} / \mathrm{s}, \\
\text { wheel rotational } \\
\text { speed }=1600 \mathrm{rpm} \text {, wheel } \\
\text { diameter }=304.8 \mathrm{~mm}, \\
\text { depth of cut }=50 \mu \mathrm{M}, \\
\text { width of cut }=25.4 \mathrm{~mm}\end{array}$ & Not applicable \\
\hline Ravuri et al. (2016) [92] & Inconel 718 & Graphene nanoplatelet & Surface grinding & $\begin{array}{l}\text { Wheel speed }=25 \mathrm{~m} / \mathrm{s} \\
\text { feed }=15 \mathrm{~m} / \mathrm{min}\end{array}$ & Not applicable \\
\hline Pavan et al. (2017) [93] & Inconel 718 & Graphene nanoplatelet & Surface grinding & $\begin{array}{l}\text { Wheel speed }=25 \mathrm{~m} / \mathrm{s}, \text { feed } \\
\text { rate }=15 \mathrm{~m} / \mathrm{min}\end{array}$ & Flow rate $=2.5 \mathrm{ml} / \mathrm{min}$ \\
\hline
\end{tabular}




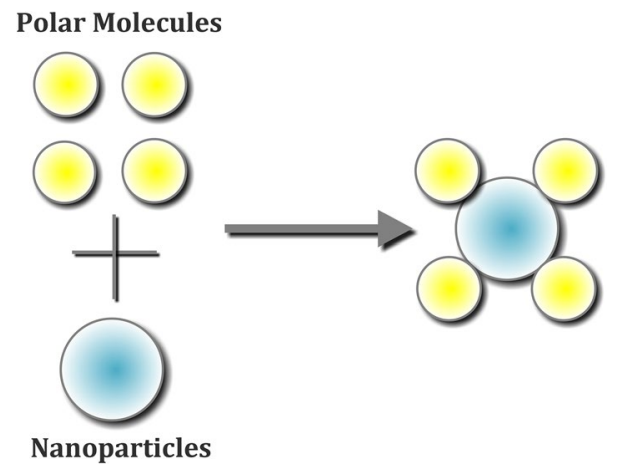

Fig. 15 Schematic of nanoparticle surface effect [100]

compressive force. The lubrication mechanism of Nanofluid is displayed in Fig. 16(a-d).

\section{Application of MQL in Diverse Machining Processes: Advantages and Limitations}

The previous sections already highlighted the applicability of vegetable oils and nanofluids in the machining domain. Thus the current segment critically assesses the research papers related to MQL assisted machining processes and reveals the merits and demerits of it.

\subsection{MQL Assisted Turning}

Turning, performed for rotational shaped products, are one of the mostly used machining processes that have adopted MQL strategies largely. The range of materials processed using turning includes steel, hardened steels, alloy steels, $\mathrm{Ni}$ and Ti-based alloys, $\mathrm{Al}$ and $\mathrm{Mg}$ alloys, etc. For instance,
Mia et al. [101] performed turning operation under MQL condition in cutting hardened steel. They have investigated the tool wear, surface roughness and material removal rate. In addition, they optimized the responses using Taguchi $\mathrm{S} / \mathrm{N}$ ratio. Dhar et al. [31] performed an experimental study on MQL assisted turning operation, whereas AISI 1040 was used as workpiece material. The researchers observed that MQL technology effectively reduced the tool-workpiece friction and cutting temperature. In addition, they observed the minimized value of secondary flank wear compared to a dry condition. Thakur et al. [102] executed an experiment on Inconel alloy and established that MQL technique could be employed to carry out machining of heat resistive superalloys, as well as the best possible machining parameters, were acquired. CheHaron et al. [103] conducted an analysis of microstructure, and it was revealed that the plastic deformation comes off in high-speed cutting, and the direction of deformation was parallel to the direction of cutting. Mia et al. [26] conducted turning with MQL with the variation in the fluid impingement flow rate as a function of time dependency and found interesting effects on the surface roughness. They concluded that the flow rate influenced the surface quality and caused improved surface when the coolant was in adequate quantity to lubricate the cutting zone. Liu et al. [104] executed turning for Ti-based alloys under MQL endeavor. For the cooling purpose, Vortex tube was utilized in the MQL setup. In actual, this study revealed the effect of vortex tube on machining responses. The results of the study signified that the vortex tube assisted MQL technology effectively reduced the surface roughness value. However, the cutting force acquired in the vortex tube supported MQL condition was slightly higher than the cutting force acquired in flood cutting. In another study, Liu et al. [105] observed that the feed rate was the most dominant
Fig. 16 a-d Lubrication mechanisms of Nanofluid [100] a

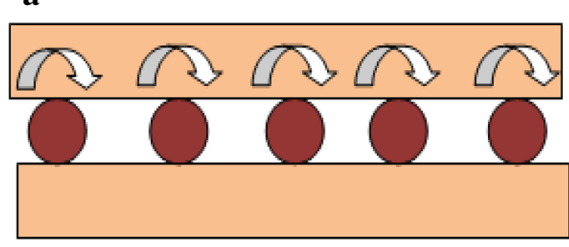

Rolling Effect

c

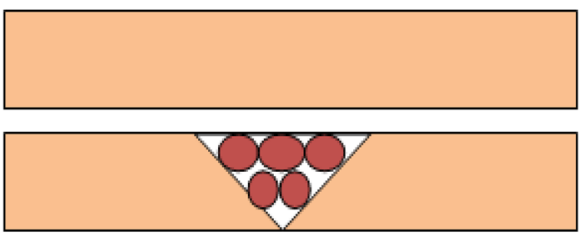

Mending Effect b

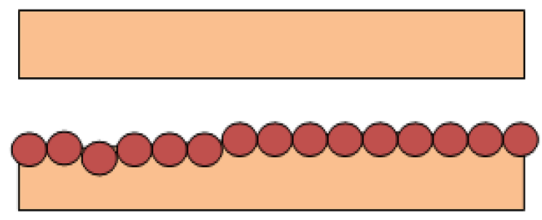

Surface Protection Film

d

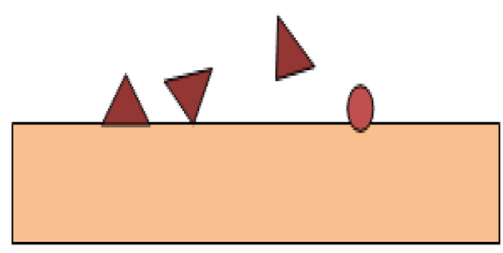

Polishing Effect 
factor affecting the machining responses. Stephenson et al. [106] observed that supercritical $\mathrm{CO}_{2}$ based MQL technology was very effective to minimize the MRR during turning operation. As compared to the flooded condition, $40 \%$ MRR can be increased using supercritical $\mathrm{CO}_{2}$. In addition, the authors also observed a tremendous increment in tool life. Sarıkaya and Güllü [107] performed a machining operation, where vegetable oil was used as MQL base fluid. For the optimization purpose, the authors used Taguchi based GRA technique. The results of this study confirmed that $30 \mathrm{~m} / \mathrm{min}$ cutting speed, $180 \mathrm{ml} / \mathrm{h}$ flow rate could effectively minimize the surface roughness and tool wear rate. The salient findings of MQL assisted turning are summarized in Table 8.

\subsection{MQL Assisted Grinding}

Though grinding is not a large quantity material removal process, its importance lies in the manufacturing of precision and ultra-precision high-performance parts. To attain extraordinary benefits, the MQL has been practiced for grinding operation. Khan et al. [108] conducted an experimental study on grinding AISI D2 steel under MQL and performed the comparison with that of dry and wet cutting. Alongside, they studied the surface topography and presented the optimization. They claimed to have better machinability using MQL than dry or flood cooling. Then, Sadeghi et al. [109] performed a grinding operation on Ti-6Al-4V material, whereas Synthetic ester and vegetable oil were used as MQL base fluid. The results of this experimental study showed that synthetic ester performed better than vegetable oil under MQL assisted grinding condition. Barczak et al. [110] conducted a grinding operation to compare the performances of three machining conditions viz. dry, flooded and MQL. The results of this comparative study confirmed that surface quality accomplished in MQL assisted grinding operation was much better than other conditions. Oliviera et al. [111] conducted the grinding of quenched and tempered steel by a CBN grinder under MQL condition. Besides that, a jet of air was also employed in the machining zone to facilitate cleaning operation. The investigation was accomplished to get roundness errors, surface roughness, wheel wear (diametrical) and metallographic pictures of the ground and subsurface. The outcomes of this study illustrated the encouraging effects of cleaning jet system as the technical development of MQL to cut the excessive utilization of lubricants. Li and Lin [112] performed an experimental study to check the influence of MQL in microgrinding operation. The researchers evidenced that MQL system was very effective to minimize surface roughness and tool wear in the micro-machining environment. Balan et al. [113] investigated the influence of MQL parameters on the grinding operation of Inconel 751. In conclusion, the authors revealed that increased MQL pressure value was very much effectual to minimize the machining responses viz. surface roughness and cutting forces. During MQL assisted grinding of 100-Cr-6, Hadad et al. [114] observed a great surface quality. On the contrary, for $42-\mathrm{Cr}-\mathrm{Mo} 4$ steel grinding, authors found a negative impact of MQL technology. In a particular study, Rabiei et al. [115] confirmed that MQL assisted grinding operation was effective for hard steel.

Table 8 Salient findings under MQL assisted turning operation

\begin{tabular}{|c|c|c|}
\hline Researchers & Machining parameters & Salient findings \\
\hline Dhar et al. (2006) [31] & $\begin{array}{l}\text { Cutting speed }=64,80,110 \text { and } 130 \mathrm{~m} / \mathrm{min} \text {, } \\
\text { feed }=0.10,0.13,0.16 \text { and } 0.20 \mathrm{~mm} / \mathrm{rev} \text {, depth of } \\
\text { cut }=1.0 \mathrm{~mm}\end{array}$ & $\begin{array}{l}\text { MQL system substantially reduced the cutting tem- } \\
\text { perature and improved dimensional accuracy }\end{array}$ \\
\hline Thakur et al. (2009) [102] & $\begin{array}{l}\text { Cutting speed }=40,60 \mathrm{~m} / \mathrm{min} \text {, feed }=0.08,0.20 \mathrm{~mm} / \\
\text { rev }\end{array}$ & $\begin{array}{l}\text { The effects of MQL in machining and optimal MQL } \\
\text { parameters were determined for Inconel } 718\end{array}$ \\
\hline CheHaron et al. (2010) [103] & $\begin{array}{l}\text { Cutting speed }=90,120 \text { and } 150 \mathrm{~m} / \mathrm{min} \text {, feed }=0.15 \text {, } \\
0.25 \text { and } 0.25 \mathrm{~mm} / \mathrm{rev} \text {, depth of cut }=0.3,0.4,0.5 \mathrm{~mm}\end{array}$ & $\begin{array}{l}\text { A mathematical model was developed for surface } \\
\text { roughness and the optimum machining parameters } \\
\text { were determined }\end{array}$ \\
\hline Liu et al. (2013a) [104] & $\begin{array}{l}\text { Cutting speed }=120 \mathrm{~m} / \mathrm{min} \text {, feed }=0.1 \mathrm{~mm} / \mathrm{rev} \text {, depth } \\
\text { of cut }=1.2 \mathrm{~mm}\end{array}$ & $\begin{array}{l}\text { MQL technology can significantly improve tool life as } \\
\text { compared to dry machining }\end{array}$ \\
\hline Liu et al. (2013b) [105] & $\begin{array}{l}\text { Cutting speed }=40,80,120,160 \mathrm{~m} / \mathrm{min}, \text { feed }=0.05 \text {, } \\
0.1,0.15,0.2 \mathrm{~mm} / \mathrm{rev} \text {, depth of cut }=0.3,0.6,0.9 \\
1.2 \mathrm{~mm}\end{array}$ & $\begin{array}{l}\text { The feed rate was the dominant factor, which mostly } \\
\text { affected machining outputs }\end{array}$ \\
\hline Stephenson et al. (2014) [106] & $\begin{array}{l}\text { Experiment series } 1 \text { : } \\
\text { Cutting speed }=45.70,45.70,50.30 \mathrm{SMM} \text {, feed }=0.25 \text {, } \\
0.25,0.30 \mathrm{~mm} / \mathrm{rev} \text {, avg. depth of cut }=03.00,3.00 \text {, } \\
3.00 \mathrm{~mm} \\
\text { Experiment series } 2: \\
\text { Cutting speed }=45.70,45.70,50.30 \mathrm{SMM} \text {, feed }=0.25 \text {, } \\
0.25,0.30 \mathrm{~mm} / \mathrm{rev} \text {, avg. depth of cut }=03.00,3.00 \text {, } \\
3.00 \mathrm{~mm}\end{array}$ & $\begin{array}{l}\text { SupercriticalCO } \mathrm{CO}_{2} \text { in } \mathrm{ML} \text { system can effectively } \\
\text { improve the tool life as well as MRR }\end{array}$ \\
\hline
\end{tabular}


Sridharan and Malkin [116] performed an experimental study to investigate the lubricating effect of minimum quantity nanofluid on grinding operation. Accordingly, they reinforced CNT and $\mathrm{MoS}_{2}$ nanoparticles on ester oil and sprayed these nanofluids into the tool-workpiece interface. The experimental results demonstrated that nanofluid behaves better in reducing specific energy and thermal distortion as compared to plain ester oil. However, flood lubrication technology shows lesser thermal distortion as compared to MQL technology. Furthermore, the FEM based thermal model was developed to simulate the thermal distortion phenomenon of grinding. Simulated results depicted that the convection coefficient (h) in MQL assisted grinding was varied from 5 to $20 \mathrm{~W} / \mathrm{m}^{2} \mathrm{~K}$ which was much lesser than flood lubrication. A few years later, Lee et al. [117] executed an experimental operation to observe the thermal characteristics in microscale grinding. The experiments were performed under compressed air, pure MQL and nanofluid based MQL conditions, wherein the sub-surface grinding temperature, and tangential grinding forces were considered as response parameters. Results demonstrated that sub-surface grinding temperature was reduced using nanofluid based MQL as compared to other conditions. In addition, nanofluids produced lesser grinding flux than other cases. Finally, a comparative study depicted that there was a close agreement between experimental and CFD based simulated results, which shows the modesty of the proposed thermal model. The salient findings of MQL assisted grinding are summarized in Table 9.

\subsection{MQL Assisted Milling}

Considering the breadth of applications the milling process in shaping the product geometries in high-performance engineering sectors such as in aircraft industries, automobile industries as well as in contemporary electronics gadgets, the milling process has been extensively explored. With milling, the necessity of cooling down the cutting zone became indispensable which triggered quite some researches. As such, Sun et al. [118] performed an MQL assisted milling operation to compare the outcomes with the dry and wet cooling condition. The comparative analysis demonstrated that MQL produced superior lubrication effect on the cutting zone. Thus the maximum tool life and minimum cutting forces were achieved as compared to other cooling conditions. Li et al. [119] executed a milling operation on Inconel 718 using coated carbide tool. The authors observed significant decrement in tool wear and cutting forces. Additionally, researchers found that flank wear was responsible for the decrement in tool life. Da Silva et al. [120] performed a comparative study on dry, flooded and MQL assisted cooling condition. The results demonstrated that greater MRR and extended machined length were attained by reduced MQL flow rate. Researchers also found that MQL is very much effectual for hardened materials to minimize the thermal cracks. Liu et al. [121] executed machining for Ti under MQL endeavor. They assorted the parameters of MQL system and observed that the variation in input parameters had a significant influence on the cutting temperature and cutting force. During the experiment, it was also monitored that the enhancement in the supply of lubricant from 2 to $14 \mathrm{ml} / \mathrm{h}$ caused a severe decrement in surface roughness. In another study, Cai et al. [30] scrutinized that the increment in the MQL fluid flow was effectual up to $10 \mathrm{ml} / \mathrm{h}$. Zhang et al. [122] accounted that tool wear occurs in machining because of brutal chipping of the cutting edge. Despite, MQL gave 1.57 times better tool life as to the dry machining. Singh et al. [34] used MQL assisted end milling process to develop an intelligent prediction and optimization model of tool wear in machining Inconel. Besides the development of such intelligent models, they found that MQL condition was superior to dry and flood cooling condition in respect of tool wear. Mia [123] performed an optimization study for the specific cutting energy and surface roughness under the variation of flow rates of MQL. It was found that MQL influenced the specific energy, i.e., energy consumption, and the surface quality of the product.

Recently, Sen et al. [61] revealed a demerit of MQL technology in milling operation. Researchers claimed that MQL technology did not alter the tool wear mechanism, but greatly reduced the rate of tool wear. In interrupted milling, cutting tool exits and enters into the workpiece material numerous times per second. In high and low-speed milling, the thermal and mechanical region of cutting tool was affected. Thus, cracks can be observed in both thermal and mechanical region of the cutting tool. MQL technology successfully reduces the cutting zone temperature, but cannot moderate the conductive heat from tool-workpiece interfaces. Thus, cracks are visible in the milling tool. Besides that in cutting operation tool heated up and rendered cold after the application of lubricant. The fluctuation in tool-tip temperature results in thermal fatigue and can be another reason for the crack propagation. The salient findings of MQL assisted milling are summarized in Table 10.

\subsection{MQL Assisted Drilling}

Drilling has been accredited as one of the mostly used manufacturing processes for parts used in ordinary applications to extraordinary engineering platforms. Use of MQL was considered in drilling for supplying enhanced lubrication. Davim et al. [124] examined the influences of the various cooling conditions during drilling of AA1050 using a k10 drill bit. The results of this study demonstrated that the performance of MQL was comparable with the flooded condition. Bhowmick et al. [125] found significant improvement in tool life during MQL assisted drilling 


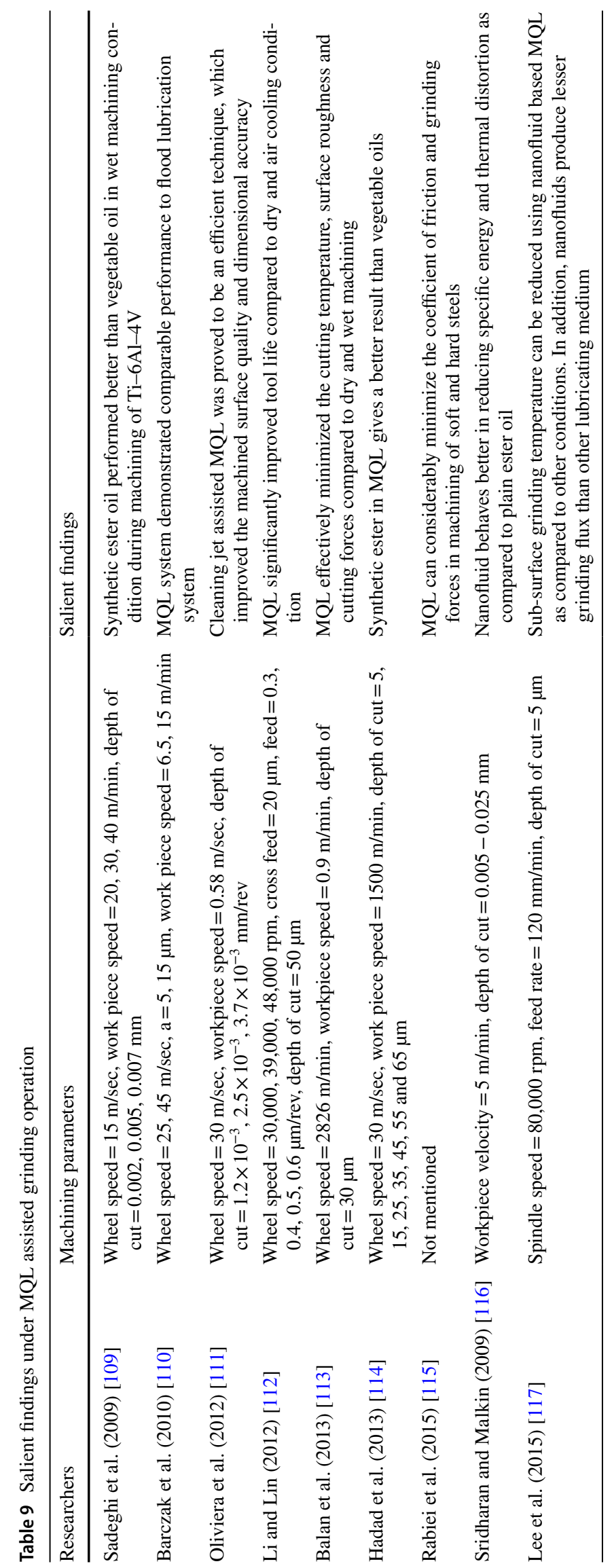


Table 10 Salient findings under MQL assisted milling operation

\begin{tabular}{|c|c|c|}
\hline Researchers & Machining parameters & Salient findings \\
\hline Sun et al. (2006) [118] & $\begin{array}{l}\text { Cutting speed }=40-140 \mathrm{~m} / \mathrm{min} \text {, feed }=0.05-0.2 \mathrm{~mm} / \\
\text { rev, axial depth of cut }=0.5 \mathrm{~mm} \text {, radial depth of } \\
\text { cut }=2-8 \mathrm{~mm} \text {, and no of tooth }=2\end{array}$ & $\begin{array}{l}\text { MQL provided a good cooling effect and reduced tool } \\
\text { wear as well as cutting temperature }\end{array}$ \\
\hline Li et al. (2006) [119] & $\begin{array}{l}\text { Axial depth of cut }=1.2 \mathrm{~mm} \text {. The width of cut }=2 \mathrm{~mm} \text {. } \\
\text { The feed per tooth }=0.03 \mathrm{~mm} \text {. The cutting } \\
\text { speeds }=30 \mathrm{~m} / \mathrm{min} \text { (spindle speed } n \text { was } 600 \mathrm{rpm} \text { ) and } \\
45 \mathrm{~m} / \mathrm{min} \text { (spindle speed } n \text { was } 900 \mathrm{rpm} \text { ) }\end{array}$ & $\begin{array}{l}\text { Flank wear was the predominant failure mode affecting } \\
\text { the tool life }\end{array}$ \\
\hline Da Silva et al. (2011) [120] & $\begin{array}{l}\text { Cutting speed }=200,260 \mathrm{~m} / \mathrm{min} \text {, depth of cut }=2 \mathrm{~mm} \text {, } \\
\text { feed rate per tooth }=0.14,0.22 \mathrm{~mm} / \mathrm{rev}\end{array}$ & $\begin{array}{l}\text { Reduced flow rate significantly improved the machined } \\
\text { length and MRR values. In addition, SEM analysis } \\
\text { demonstrated that the tool wears highly affected by } \\
\text { machining environment }\end{array}$ \\
\hline Liu et al. (2011) [121] & $\begin{aligned} \text { Cutting speed } & =150 \mathrm{~m} / \mathrm{min}, \text { feed }=0.05 \mathrm{~mm} / \text { tooth, axial } \\
\text { depth of cut } & =5 \mathrm{~mm}, \text { radial depth of cut }=1 \mathrm{~mm}\end{aligned}$ & $\begin{array}{l}\text { MQL has a significant effect on cutting forces and cutting } \\
\text { temperature. Too large or too small values of spraying } \\
\text { distance and air pressure were not good to get better } \\
\text { penetrability of the lubricants }\end{array}$ \\
\hline Cai et al. (2012) [30] & $\begin{aligned} \text { Cutting speed } & =200 \mathrm{~m} / \mathrm{min}, \text { feed }=0.25 \mathrm{~mm} / \text { tooth, axial } \\
\text { depth of cut } & =5 \mathrm{~mm} \text {, radial depth of cut }=1 \mathrm{~mm}\end{aligned}$ & $\begin{array}{l}\text { The rate of oil supply (up to } 10 \mathrm{ml} / \mathrm{h} \text { ) significantly } \\
\text { reduced surface roughness as well as cutting forces }\end{array}$ \\
\hline Zhang et al. (2012) [122] & $\begin{array}{l}\text { Cutting speed }=55 \mathrm{~m} \mathrm{~min}^{-1} \text { (spindle speed } \mathrm{n}=875 \mathrm{rev} / \\
\mathrm{min} \text { ), feed per tooth }=0.1 \mathrm{~mm} / \text { tooth, axial depth of } \\
\text { cut }=0.5 \mathrm{~mm} \text {, radial depth of cut }=1 \mathrm{~mm}\end{array}$ & $\begin{array}{l}\text { MQCL can effectively maximize the machinability and } \\
\text { tool life and minimized cutting forces }\end{array}$ \\
\hline
\end{tabular}

of magnesium alloy. In another study, Bhowmick and Alpas [126] declared that MQL assisted drilling operation required less torque as compared to the dry and wet drilling operation. Rahim and Sasahara [127] executed a drilling operation in Inconel 718, whereas synthetic ester and palm oil were used as MQL base fluid. The researchers observed that both lubricants could effectively minimize surface defects, micro-cracks, and surface roughness. FoxRabinovich et al. [128] examined the influences of tool coatings in the tool life considering two cooling conditions viz. flooded and MQL. The results of this study confirmed that tool life could be maximized by applying MQL cooling technique. Kilickap et al. [129] performed a drilling operation on Al-7075 alloy and found desirable machining responses using MQL technology. Brinksmeier et al. [130] studied the influences of MQL technology on the drilling operation. The outcomes of this study depicted that internally lubricated MQL system produced 50\% less cutting temperature as compared to externally lubricated MQL system. The salient findings of MQL assisted drilling are summarized in Table 11.

On the light of the above literature investigation, the accumulated benefits of the use of MQL and associated demerits are listed in Table 12. However, MQL technology still needs significant improvement concerning lubricity and cooling. Because few researchers have found negative impacts of MQL in machining domain [37, 131]. Thus, advancement in MQL system is an essential task to make it more compatible for lubrication and cooling purposes. The advanced MQL developments will be conferred in the subsequent section.

\section{Recent Advancements in MQL System}

About a decade back, the idea of MQL was introduced with an aim to minimize the health and environmental hazards. At first, conventional fluids mixed with compressed air were applied in the cutting zone through MQL system. In modern days, the vegetable and nanofluids are widely used in MQL system due to their superior lubricity. Furthermore, some scholars have been discovered following ideas to improve the efficiency of the MQL system. Others are working to combine MQL with cryogenic coolants [132, 133], some showed electrostatic MQL [134].

\subsection{MQL with lonic Liquid}

Ionic liquids are organic salt having a low melting point. Due to the excellent lubrication properties, it is widely applied in the area of two mating parts. Conversely, low volatility of ionic liquid has inspired investigators to extend their research work with ionic liquid [135]. Researchers reported that using ionic liquid 15-60\% tool wear can be minimized during machining of $\mathrm{Ti}$ when compared with other cooling condition [136]. Goindi et al. [137] conducted the milling operation on AISI 1045 carbon steel and reported that the performance of ionic liquid on MQL was equivalent to that of flood cooling. Pham et al. [138] found Superior surface quality in the micro-machining of Al 5052. Recently, Sani et al. [139] showed a schematic diagram on the action of ionic liquid on sliding surfaces (Fig. 17). 


\subsection{MQL with Ranque-Hilsch Vortex Tube}

The RHVT is a mechanical device, which separates hot and cold streams from compressed air. It doesn't comprise any moving/revolving parts. Without using electricity or chemicals, it can separate a stream having a different temperature [140, 141]. Maximum performance of RHVT was found, when the temperature gradient between two streams are more than $97{ }^{\circ} \mathrm{C}$ [142]. Liu et al. [143] observed that the tool wear could be minimized by the use of RHVT. In an experimental study on RHVT, Boswell et al. [144] obtained a superior surface finish and minimum cutting force for aluminium alloy. Recently, Mia et al. [145] observed reasonable decrement in surface roughness and tool wear by using RHVT and nitrogen gas in MQL assisted turning and recommends novel cooling technologies in a machining operation.

\subsection{MQL with Cryogenic Cooling}

In cryogenic MQL, gases are liquefied at or below $-150{ }^{\circ} \mathrm{C}$ and sprayed through a specially fabricated nozzle. This cooling method was very popular and widely applied in different machining operations including turning [146, 147], milling [148, 149], grinding [150] and drilling [151]. Su et al. [152] noted $124 \%$ increment in tool life during machining of Inconel 718 under Cryogenic MQL conditions, and few more improved results were found in other literature also [153-155]. Busch et al. [156] investigated multiple modes of cooling lubrication, among which, the aerosol lubrication with $\mathrm{CO}_{2}$ was found to provide sufficient lubrication, provided that an optimized condition is used. On an advanced level, the hybrid use of MQL with $\mathrm{N}_{2}$ or $\mathrm{CO}_{2}$ is reported by Sartori et al. [157]. Their prime target was to reduce the tool wear, for which they successfully claimed to have reduced crater wear and surface quality. Pusavec et al. $[158,159]$ in their successive papers reported the investigation and modeling of the sustainable manufacturing of Inconel parts using conventional and hybrid cooling lubrication strategies. The use of MQL and the cryogenic system showed improved results. They have also formulated prediction and optimization models for the highest level of sustainability.

\subsection{MQL with Supercritical Carbon Dioxide $\left(\mathrm{scCO}_{2}\right)$}

Supercritical $\mathrm{CO}_{2}$ has a beautiful aroma, excellent solubility, and limited heat dispersion capability, thus applied as a lubricant in the metalworking domain $[160,161]$. It has been observed that $\mathrm{CO}_{2}$ in MQL can effectively reduce the surface finish, wheel wear, and energy consumption compared to flood cooling technology $[162,163]$. However, the application of $\mathrm{CO}_{2}$ during machining is provocative because it is one of the major greenhouse gases. To determine the efficacy of the above processes, Boswell et al. [164] performed a 
Table 12 Merits and demerits of MQL assisted machining processes

\begin{tabular}{|c|c|c|}
\hline Type of machining & Merits & Demerits \\
\hline MQL Turning & $\begin{array}{l}\text { Effectively reduces surface roughness and tool wear } \\
\text { Promotes green manufacturing by reducing disposals } \\
\text { Considerable reduction in cutting temperature thus produces } \\
\text { superior dimensional accuracy } \\
\text { Effectively lubricate the cutting zone, thus minimizes the } \\
\text { cutting forces }\end{array}$ & $\begin{array}{l}\text { Does not resist corrosion } \\
\text { Unable to clear metal chips from the machining zone } \\
\text { The filtering process of the mist is hazardous to the operators }\end{array}$ \\
\hline MQL Grinding & $\begin{array}{l}\text { Significantly increases the surface quality } \\
\text { Minimum blockage of the wheel used in the grinding pro- } \\
\text { cess due to impingement of high-pressure air and mist of } \\
\text { oil on the wheel and workpiece boundary } \\
\text { Environmental and Economic advantages are acquired } \\
\text { Very few harmful residuals are generated } \\
\text { Grinding swarf can be easily washed out from cutting zone }\end{array}$ & Not suitable for dressing process \\
\hline MQL Milling & $\begin{array}{l}\text { Improves tool life as well as MRR } \\
\text { Fewer detrimental residuals to be disposed of } \\
\text { Considerably better surface finish compared to dry and } \\
\text { flooded condition } \\
\text { A significant drop in cutting forces and temperature }\end{array}$ & $\begin{array}{l}\text { Complexity in maintaining a similar concentration of cutting } \\
\text { fluid through every nozzle } \\
\text { Specially fabricated nozzles are needed for using oil mist, } \\
\text { which increases the equipment cost }\end{array}$ \\
\hline MQL Drilling & $\begin{array}{l}\text { Significantly improves the surface integrity with microhard- } \\
\text { ness } \\
\text { Prevent built-up edge formation } \\
\text { Helps to reduce friction, thus increases tool life }\end{array}$ & $\begin{array}{l}\text { In deep hole drilling, the MQL technique is ineffective } \\
\text { Unable to wash out chips from the cutting edge }\end{array}$ \\
\hline
\end{tabular}

Fig. 17 The action of ionic liquid in the cutting zone [139]

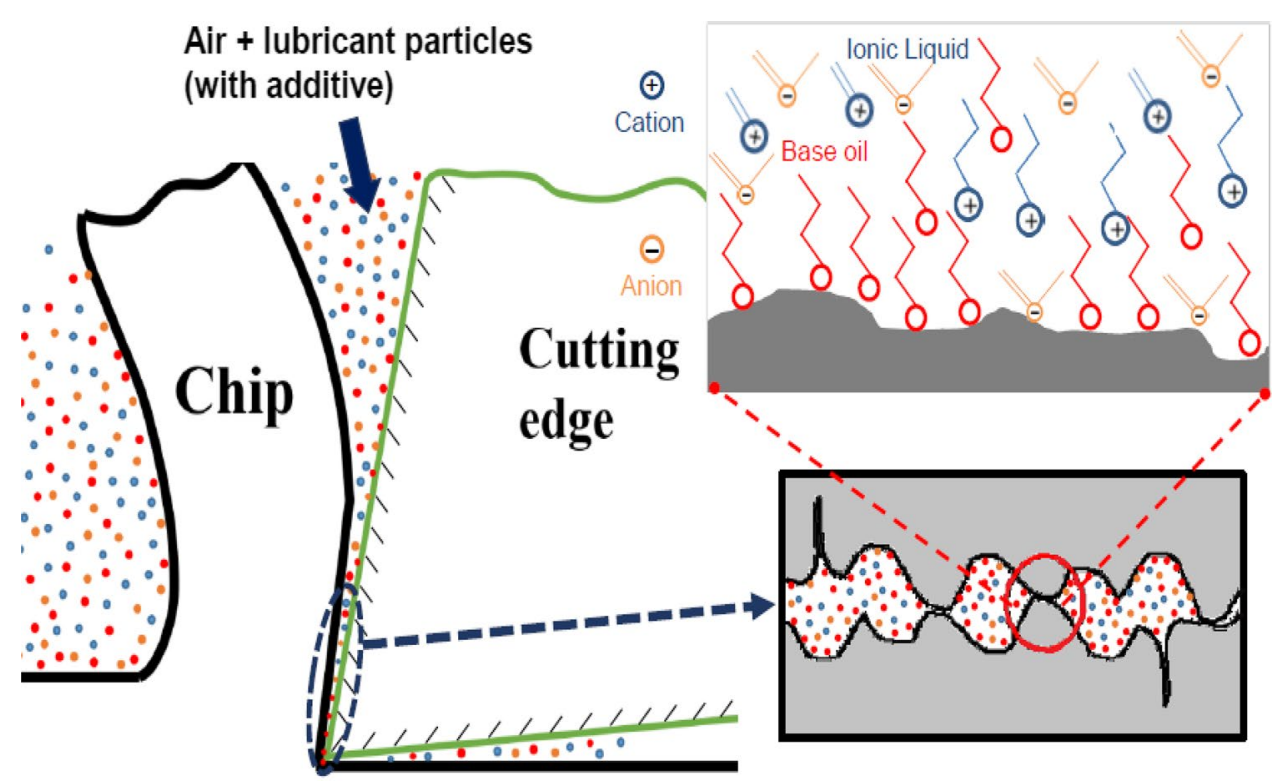

comparative study, where surface roughness, cutting forces, tool life, and tool wear were considered as performance parameters (Table 13). It was depicted from the comparative study that nanofluid based MQL system performed better than other advanced techniques. 
Table 13 Comparison of MQL developments [149]

\begin{tabular}{llllll}
\hline $\begin{array}{l}\text { Types of MQL/ } \\
\text { improvement }\end{array}$ & $\begin{array}{l}\text { MQL+nano } \\
\text { particles }\end{array}$ & $\begin{array}{l}\text { MQL+ionic } \\
\text { liquid }\end{array}$ & MQL+RHVT & $\begin{array}{l}\text { Cryogenic } \\
\text { MQL }\end{array}$ & MQL+scCO \\
\hline Tool wear & $\checkmark$ & $\checkmark$ & & $\checkmark$ \\
Tool life & $\checkmark$ & $\checkmark$ & $\checkmark$ & $\checkmark$ \\
Surface quality & $\checkmark$ & $\checkmark$ & $\checkmark$ & $\checkmark$ \\
Cutting forces & $\checkmark$ & $\checkmark$ & & $\checkmark$ & \\
\hline
\end{tabular}

Table 14 A comprehensive framework for sustainability evaluation of various machining processes [152, 153]

\begin{tabular}{|c|c|c|c|}
\hline Performances & Wet machining & Dry machining & MQL machining \\
\hline Wastage & High wastage & Zero wastage & Low wastage \\
\hline Coolant consumption & High coolant consumption & No coolant & Very low \\
\hline Scrap disposals & Scrap has deposition of fluid over it & Scrap is free from the fluid & $\begin{array}{l}\text { The scrap is clean, and no } \\
\text { treatment is required }\end{array}$ \\
\hline Part cleaning & High part cleaning is required & No part cleaning is required & No part cleaning is required \\
\hline Health issues & Highly toxic & Totally safe & Almost safe \\
\hline Power consumption & Medium & High & Low \\
\hline Manufacturing cost & High & Low & Low \\
\hline Equipment required & Pumps, nozzles, pipes etc. & No need for any types of equipment & MQL setup is required \\
\hline
\end{tabular}

\section{Review on MQL Technology}

\subsection{Review from the Perspective of Sustainability}

Sustainability has introduced many conditions in machining, but MQL technology catches the great attention of researchers because of its unique philosophy "more is not always better". MQL technology eliminates the use of conventional coolant and substitutes them with a small amount of lubricant-air mixture in the metal cutting operation. The lubricant/oil used for MQL is generally vegetable oil or nanofluid, which protects the environment and also minimizes the lubrication cost of machining.

Previous literature already showed the superior advantages of MQL technology in machining. Now to quantify the sustainability of MQL technology, we have shown a brief comparative analysis of three modes of machining processes. Various sustainability aspects regarding wastage, coolant consumption, scrap disposals, part cleaning, health issues, power consumption, manufacturing cost and equipment required have been considered in this comparative study (Table 14). The outcomes of this comparative study advocated that dry and MQL machining are the best practice in terms of sustainability and environmental aspects. However, if we consider the performance measures regarding sustainability and machinability both then the application of MQL is found to be the most viable

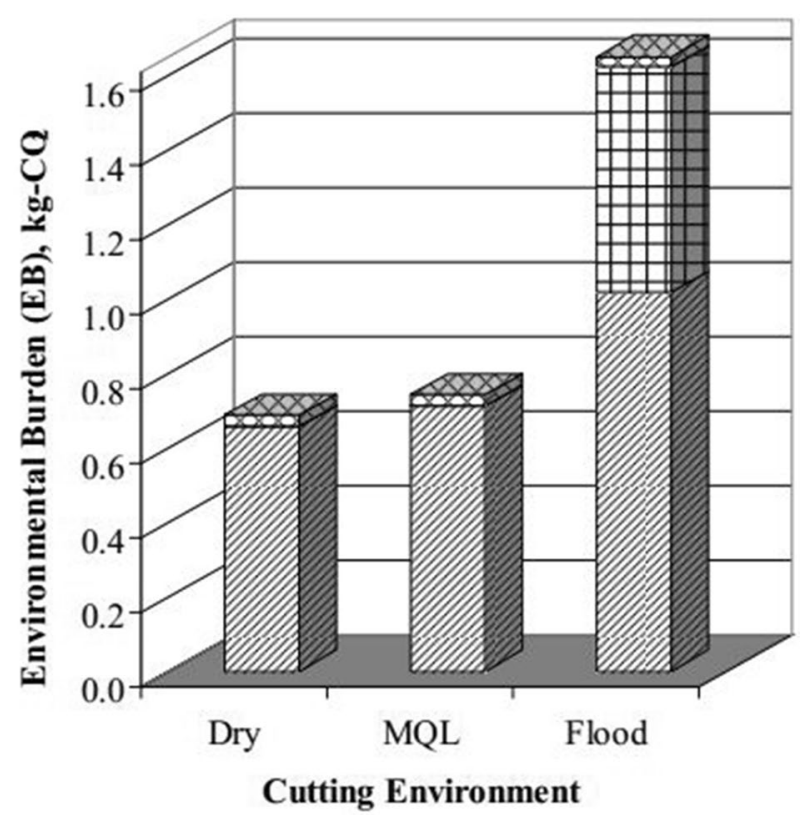

\begin{tabular}{|ll|}
\hline Electrical Energy & $\boxplus$ Cutting Fluid disposal \\
四 Cutting tool disposal & $\otimes$ Chips disposal \\
\hline
\end{tabular}

Fig. 18 A comparative analysis of dry, MQL and flood cooling based on environmental burden perspective [165] 
Fig. 19 LCA summery for different cooling techniques [166]

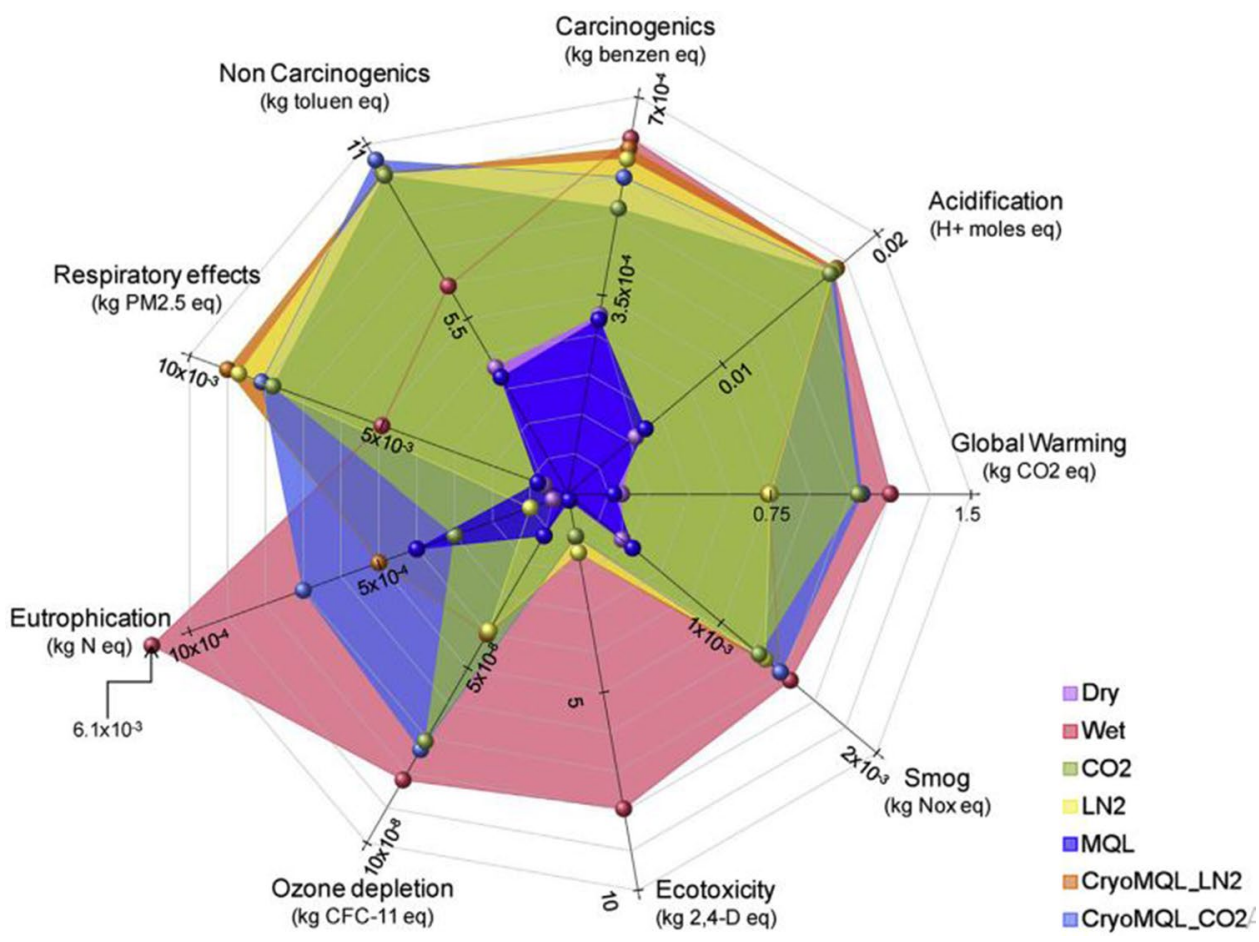

option. Furthermore, during the LCA of different cooling techniques, Mulyadi [165] investigated that flood lubrication technique has the maximum environmental burden while MQL and dry machining have the minimum negativities (Fig. 18 ), and this outcome was consistent with the finding of Pereira et al. [166] (Fig. 19).

\subsection{Review from the Perspective of Economy and Ecology}

Manufacturing companies are changing their working policy to reduce machining cost, ecological impacts, and health issues; thus they are making a transition from conventional lubrication to MQL strategy. Although, MQL is considered as economically viable because of less cutting fluid consumption, and low set up cost [167]. Benedicto et al. [168] claimed that MQL technology could reduce the machining cost up to $95 \%$. In addition, this technology could enhance the tool life, and reduces cutting fluid recycling cost up to great extent. In contrary, Skerlos et al. [167] revealed that if the environmental, and ecological issues were not considered, then manufacturing units were reluctant to change the conventional technology, because of high set up cost of MQL. The high price is the primary barrier for vegetable oil and nanofluid based lubricants. The prices of vegetable oil are not competitive in comparison with conventional lubricants. Even vegetable oils are eight times more expensive than conventional lubricants [169]. In addition, the high manufacturing cost of nanoparticles, and their waste treatment cost acts as a barrier for its usages in manufacturing industries. The prevention of their agglomeration and sedimentation is also a challenging task for the workers [170]. However, vegetable oils and nanofluids are gaining interest from the last decade as an alternative to conventional lubricants in MQL assisted machining environment.

MQL technology drastically reduces the utilization of cutting fluids in machining operation. The utilized cutting fluids are so low in amounts that eliminated the problems of cutting fluid disposal [171]. Additionally, the produced chips are so clean; thus they can be easily recycled. However, the main drawbacks of MQL are the mist generation, which may be harmful to human bodies. In addition, gas compressor consumes power to supply the compressed gas, and it may increase the global warming potential. Biodegradability is the main reason for selecting vegetable oil as MQL base fluid. The synthetic ester present in vegetable oil possesses high biodegradability [172]. Nevertheless, nanoparticles are considered as a potential source of environmental damage. The airborne nanoparticles are toxic in nature and put an adverse effect on human health [173]. A few investigations have been conducted by the researchers on the ecological, and environmental impacts of the nanofluids in machining operation. However, based on the analysis of Benedicto et al. [168], sustainability versus cost plot for different lubrication strategy is shown in Fig. 20. 
Fig. 20 Qualitative assessment of sustainability and cost in different lubri-cooling strategy [168]

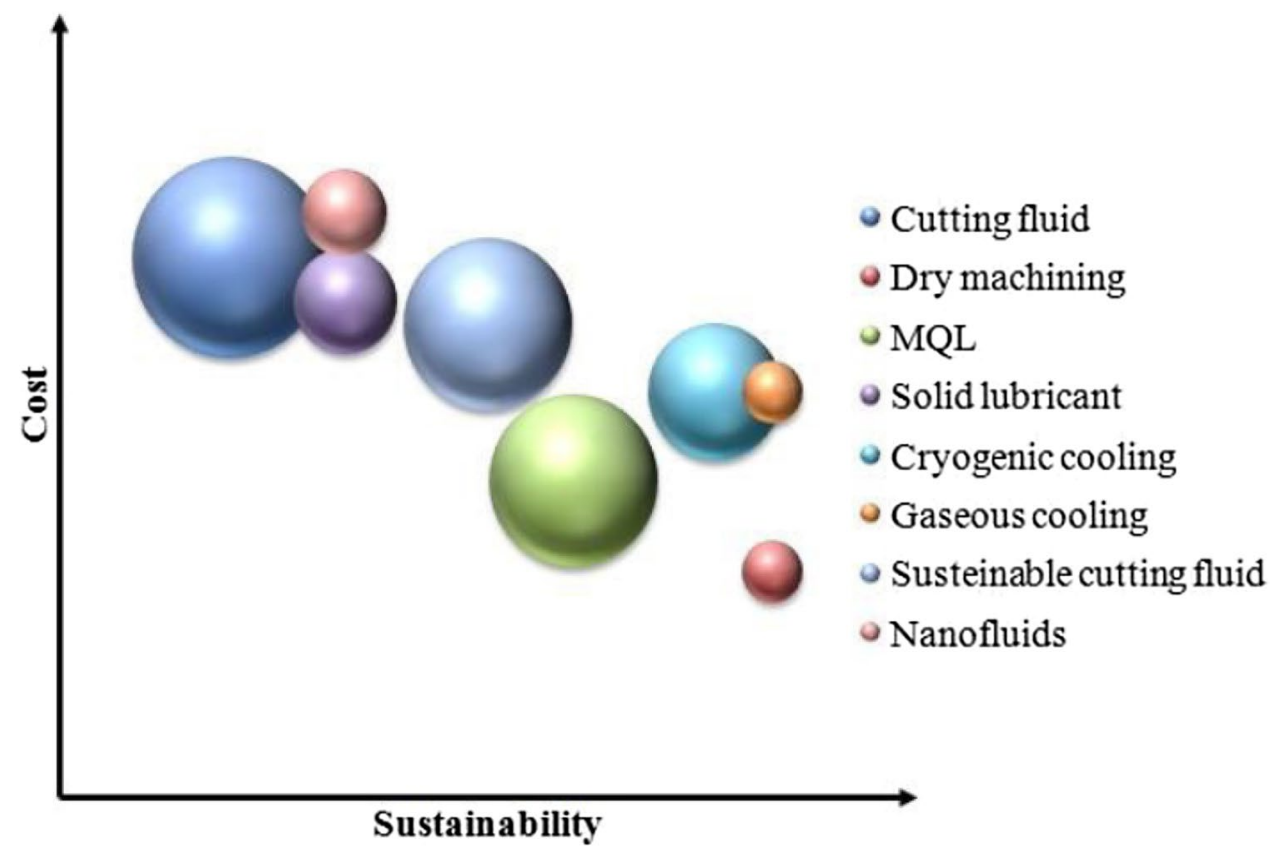

\section{Summary and Final Remarks}

A sustainable manufacturing environment not only facilitates an organization by reducing machining cost but also improves the machining efficiency and business competitiveness. Contemplating these issues, the present review work summarized the content of previously published papers regarding MQL assisted machining operations and also highlighted the merits and demerits of MQL technology. Most of the previously published documents depicted that the utilization of MQL system in machining endeavor is a viable substitute to the conventional flood lubrication technology. However, further investigation is required to make it a feasible choice for the manufacturing industries. The primary executions of this review paper are listed below:

- Application of MQL technology effectively minimizes the machining performances viz. surface roughness, cutting force, cutting temperature and tool wear. Nevertheless, few important MQL parameters like air pressure, air-oil mixture, number of nozzles, nozzle distance and nozzle angle has put a significant impact on machining performances. The performance of MQL was also varied with the tool material, tool coating, and workpiece material. In addition, based on the working fluid of the MQL system, a systematic selection of machining parameters are required to get the maximum machining efficiency.

- As compared with the conventional flood lubrication technology, vegetable oils in MQL system achieved a lower value of surface roughness, cutting force, cutting temperature and tool wear. The polar groups like $-\mathrm{COOH}$ and - COOR presented in the molecules of vegetable oil helped to form a molecular film on the metal surface, thus reduced the friction and wear in machining endeavor. Indeed, a comparative analysis demonstrated that castor oil possesses the best lubricity as compared to other vegetable oils.

- Nanoparticles and nanoplatelets diffused in the MQL base fluid are a useful technique to minimize friction throughout the machining process. With the exceptional properties and minimum cost, nanoparticles and nanoplatelets are considered to be a novel, effectual choice to flood lubrication because of environmental issues. Furthermore, previous experimental studies showed that $\mathrm{Al}_{2} \mathrm{O}_{3}$ nanofluid is the best choice as a lubricant for the machining operation. Indeed, circularly shaped $\mathrm{Al}_{2} \mathrm{O}_{3}$ nanoparticles were revolved between tool-workpiece interfaces and converted the sliding into rolling-sliding friction.

- A substantial amount of previous literature witnessed that MQL technology has a great potential to improve various aspects of conventional machining namely turning, grinding, milling and drilling. Furthermore, few researchers founded negative impacts of MQL in grinding operation. Thus, advancement in MQL system is an essential task to make it more compatible for lubrication and cooling purposes. Nevertheless, a comparative study demonstrated that nanofluid based MQL system performed better than other advanced techniques namely MQL with the ionic liquid, MQL with RHVT, Cryogenic MQL and MQL with supercriticalCO ${ }_{2}$.

- Previous literature also advocated that dry and MQL machining are the best practice regarding sustainability and environmental aspects. However, if we consider the 
performance measures in terms of both the sustainability and machinability, then the application of MQL is found to be the most viable option.

\section{Future Scope}

MQL technology has a great potential to perform well in the experimental endeavor, despite that fact, the long term potential for industrial operation remains unanswered. This issue might be solved when more works will be accomplished in industries for large scale production. Here, we found a few gaps in the previous literature and propose these gaps as the future scope of the study, which is listed below:

- Investigation of toxicity of nanoparticles and ionic liquids is an essential task to increase the application of MQL technology in the near future.

- In recent times, a couple of papers were published involving the benefits of hybrid nanoparticles and showed that the hybrid nanoparticles are very useful to improve the lubricity of MQL base fluid. Thus, the authors recommend further investigation of hybrid nanoparticle-based MQL technology.

- A field survey is required to be published on the actual industrial application of MQL. For this purpose, the LCA tool would be a good choice.

- Study of the droplet dynamics of MQL base fluid will be a new research dimension. Here, the thermal analysis needs to be incorporated with sustainability analysis for green manufacturing technology.

- Furthermore, considering the potential of nanofluids in MQL, more studies are required to develop the models of tribo-film formation, heat transfer by MQL, suspension of nanoparticles, wetting ability of sprayed droplets, etc.

- Lastly, the advent of advanced computational algorithms and data science demand to be integrated with MQL assisted machining, and MQL control parameters so that intelligent and smart manufacturing can be devised for Industry 4.0. Studies are required in this field.

Acknowledgements This work was supported by the National Centre of Science (Decision No. 2017/25/B/ST8/00962) "Modeling of dynamics and strength problems during precision milling with micro ball end mills."

Open Access This article is distributed under the terms of the Creative Commons Attribution 4.0 International License (http://creativeco mmons.org/licenses/by/4.0/), which permits unrestricted use, distribution, and reproduction in any medium, provided you give appropriate credit to the original author(s) and the source, provide a link to the Creative Commons license, and indicate if changes were made.

\section{References}

1. Mia, M., \& Dhar, N. R. (2018). Effects of duplex jets highpressure coolant on machining temperature and machinability of Ti-6Al-4V superalloy. Journal of Materials Processing Technology, 252, 688-696. https://doi.org/10.1016/j.jmatprotec 2017.10.040.

2. Masoudi, S., Esfahani, M. J., Jafarian, F., \& Mirsoleimani, S. A. (2019). Comparison the effect of MQL, wet and dry turning on surface topography, cylindricity tolerance and sustainability. International Journal of Precision Engineering and Manufacturing-Green Technology. https://doi.org/10.1007/s40684-01900042-3.

3. Shokrani, A., Dhokia, V., \& Newman, S. T. (2012). Environmentally conscious machining of difficult-to-machine materials with regard to cutting fluids. International Journal of Machine Tools and Manufacture, 57, 83-101.

4. Weinert, K., Inasaki, I., Sutherland, J., \& Wakabayashi, T. (2004). Dry machining and minimum quantity lubrication. CIRP Annals-Manufacturing Technology, 53(2), 511-537.

5. Inasaki, I. (2012). Towards symbiotic machining processes. International Journal of Precision Engineering and Manufacturing, 13(7), 1053-1057.

6. Goldberg, M. (2012). Improving productivity by using innovative metal cutting solutions with an emphasis on green machining. International Journal of Machining and Machinability of Materials, 12(1-2), 17-125.

7. Boswell, B., Islam, M. N., Davies, I. J., Ginting, Y. R., \& Ong, A. K. (2017). A review identifying the effectiveness of minimum quantity lubrication (MQL) during conventional machining. The International Journal of Advanced Manufacturing Technology, 92(1), 321-340. https://doi.org/10.1007/s00170-017-0142-3.

8. Klocke, F., \& Eisenblätter, G. (1997). Dry cutting. CIRP Annals, 46(2), 519-526.

9. Iyappan, S. K., \& Ghosh, A. (2019). Small quantity lubrication assisted end milling of aluminium using sunflower oil. International Journal of Precision Engineering and ManufacturingGreen Technology. https://doi.org/10.1007/s40684-019-00081-w.

10. Khan, A. M., Jamil, M., Salonitis, K., Sarfraz, S., Zhao, W., He, N., et al. (2019). Multi-objective optimization of energy consumption and surface quality in nanofluid sqcl assisted face milling. Energies, 12(4), 710.

11. ManojKumar, K., \& Ghosh, A. (2015). Synthesis of MWCNT nanofluid and evaluation of its potential besides soluble oil as micro cooling-lubrication medium in SQL grinding. The International Journal of Advanced Manufacturing Technology, 77(9), 1955-1964. https://doi.org/10.1007/s00170-014-6587-8.

12. Dixit, U. S., Sarma, D., \& Davim, J. P. (2012). Environmentally friendly machining. Berlin: Springer Science \& Business Media.

13. Sharma, V. S., Dogra, M., \& Suri, N. (2009). Cooling techniques for improved productivity in turning. International Journal of Machine Tools and Manufacture, 49(6), 435-453.

14. Sharma, V., Dogra, M., \& Suri, N. (2008). Advances in the turning process for productivity improvement-a review. Proceedings of the Institution of Mechanical Engineers, Part B: Journal of Engineering Manufacture, 222(11), 1417-1442.

15. Varadarajan, A., Philip, P., \& Ramamoorthy, B. (2002). Investigations on hard turning with minimal cutting fluid application (HTMF) and its comparison with dry and wet turning. International Journal of Machine Tools and Manufacture, 42(2), 193-200.

16. Astakhov, V. P. (2008). Ecological machining: near-dry machining. In Machining (pp. 195-223). London: Springer.

17. Khan, M., Mithu, M., \& Dhar, N. (2009). Effects of minimum quantity lubrication on turning AISI 9310 alloy steel using 
vegetable oil-based cutting fluid. Journal of Materials Processing Technology, 209(15), 5573-5583.

18. Attanasio, A., Gelfi, M., Giardini, C., \& Remino, C. (2006). Minimal quantity lubrication in turning: effect on tool wear. Wear, 260(3), 333-338.

19. Obikawa, T., Kamata, Y., Asano, Y., Nakayama, K., \& Otieno, A. W. (2008). Micro-liter lubrication machining of Inconel 718. International Journal of Machine Tools and Manufacture, 48(15), 1605-1612.

20. Kamata, Y., \& Obikawa, T. (2007). High speed MQL finishturning of Inconel 718 with different coated tools. Journal of Materials Processing Technology, 192-193, 281-286. https:// doi.org/10.1016/j.jmatprotec.2007.04.052.

21. Maruda, R. W., Krolczyk, G. M., Nieslony, P., Wojciechowski, S., Michalski, M., \& Legutko, S. (2016). The influence of the cooling conditions on the cutting tool wear and the chip formation mechanism. Journal of Manufacturing Processes, 24, 107-115. https://doi.org/10.1016/j.jmapro.2016.08.006.

22. Mia, M., Morshed, M. S., Kharshiduzzaman, M., Razi, M. H., Mostafa, M. R., Rahman, S. M. S., et al. (2018). Prediction and optimization of surface roughness in minimum quantity coolant lubrication applied turning of high hardness steel. Measurement, 118, 43-51. https://doi.org/10.1016/j.measurement.2018.01.012.

23. An, Q., \& Dang, J. (2019). Cooling effects of cold mist jet with transient heat transfer on high-speed cutting of titanium alloy. International Journal of Precision Engineering and Manufacturing-Green Technology. https://doi.org/10.1007/s40684-01900076-7.

24. Tai, B. L., Stephenson, D. A., Furness, R. J., \& Shih, A. J. (2014). Minimum quantity lubrication (MQL) in automotive powertrain machining. Procedia CIRP, 14, 523-528.

25. Nath, C., Kapoor, S. G., DeVor, R. E., Srivastava, A. K., \& Iverson, J. (2012). Design and evaluation of an atomizationbased cutting fluid spray system in turning of titanium alloy. Journal of Manufacturing Processes, 14(4), 452-459. https:// doi.org/10.1016/j.jmapro.2012.09.002.

26. Mia, M., Razi, M. H., Ahmad, I., Mostafa, R., Rahman, S. M. S., Ahmed, D. H., et al. (2017). Effect of time-controlled MQL pulsing on surface roughness in hard turning by statistical analysis and artificial neural network. The International Journal of Advanced Manufacturing Technology, 91(9), 3211-3223. https ://doi.org/10.1007/s00170-016-9978-1.

27. Pervaiz, S., Anwar, S., Qureshi, I., \& Ahmed, N. (2019). Recent advances in the machining of titanium alloys using minimum quantity lubrication (MQL) based techniques. International Journal of Precision Engineering and Manufacturing-Green Technology, 6(1), 133-145. https://doi.org/10.1007/s4068 4-019-00033-4.

28. Dureja, J., Singh, R., Singh, T., Singh, P., Dogra, M., \& Bhatti, M. S. (2015). Performance evaluation of coated carbide tool in machining of stainless steel (AISI 202) under minimum quantity lubrication (MQL). International Journal of Precision Engineering and Manufacturing-Green Technology, 2(2), 123-129.

29. Rahman, M., Kumar, A. S., \& Salam, M. (2002). Experimental evaluation on the effect of minimal quantities of lubricant in milling. International Journal of Machine Tools and Manufacture, 42(5), 539-547.

30. Cai, X. J., Liu, Z. Q., Chen, M., \& An, Q. L. (2012). An experimental investigation on effects of minimum quantity lubrication oil supply rate in high-speed end milling of Ti-6Al-4V. Proceedings of the Institution of Mechanical Engineers, Part B: Journal of Engineering Manufacture, 226(11), 1784-1792.

31. Dhar, N. R., Islam, M. W., Islam, S., \& Mithu, M. A. H. (2006). The influence of minimum quantity of lubrication (MQL) on cutting temperature, chip and dimensional accuracy in turning
AISI-1040 steel. Journal of Materials Processing Technology, 171(1), 93-99. https://doi.org/10.1016/j.jmatprotec.2005.06.047.

32. Hadad, M., \& Sadeghi, B. (2012). Thermal analysis of minimum quantity lubrication-MQL grinding process. International Journal of Machine Tools and Manufacture, 63, 1-15. https://doi. org/10.1016/j.ijmachtools.2012.07.003.

33. Jang, D.-Y., Jung, J., \& Seok, J. (2016). Modeling and parameter optimization for cutting energy reduction in MQL milling process. International Journal of Precision Engineering and Manufacturing-Green Technology, 3(1), 5-12. https://doi.org/10.1007/ s40684-016-0001-y.

34. Singh, G., Gupta, M. K., Mia, M., \& Sharma, V. S. (2018). Modeling and optimization of tool wear in MQL-assisted milling of Inconel 718 superalloy using evolutionary techniques. The International Journal of Advanced Manufacturing Technology, 97(1), 481-494. https://doi.org/10.1007/s00170-018-1911-3.

35. Upadhyay, V., Jain, P., \& Mehta, N. (2013). Machining with minimum quantity lubrication: a step towards green manufacturing. International Journal of Machining and Machinability of Materials, 13(4), 349-371.

36. Maruda, R. W., Krolczyk, G. M., Feldshtein, E., Pusavec, F., Szydlowski, M., Legutko, S., et al. (2016). A study on droplets sizes, their distribution and heat exchange for minimum quantity cooling lubrication (MQCL). International Journal of Machine Tools and Manufacture, 100, 81-92.

37. Krolczyk, G. M., Maruda, R. W., Krolczyk, J. B., Wojciechowski, S., Mia, M., Nieslony, P., et al. (2019). Ecological trends in machining as a key factor in sustainable production-A review. Journal of Cleaner Production, 218, 601-615. https://doi. org/10.1016/j.jclepro.2019.02.017.

38. Kuo, C., Yang, J., \& Wen, J. (2019). Wear behaviour and sustainability of coated abrasives in grinding of aluminium alloy using minimum quantity lubrication. International Journal of Precision Engineering and Manufacturing-Green Technology. https:// doi.org/10.1007/s40684-019-00108-2.

39. http://www.cdc.gov/niosh/98-102-g.pdf. Accessed 10 Sept 2011.

40. Jawahir, I., \& Dillon, O. Sustainable manufacturing processes: new challenges for developing predictive models and optimization techniques. In Proceedings of the first international conference on sustainable manufacturing, Montreal, Canada, 2007 (pp. $1-19)$.

41. Denyer, D., \& Tranfield, D. (2009). Producing a systematic review. The Sage handbook of organizational research methods, 2009, 671-689.

42. Sidik, N. A. C., Samion, S., Ghaderian, J., \& Yazid, M. N. A. W. M. (2017). Recent progress on the application of nanofluids in minimum quantity lubrication machining: a review. International Journal of Heat and Mass Transfer, 108, 79-89.

43. Sen, B., Mia, M., Mandal, U. K., Dutta, B., \& Mondal, S. P. (2019). Multi-objective optimization for MQL-assisted end milling operation: an intelligent hybrid strategy combining GEP and NTOPSIS. Neural Computing and Applications. https://doi. org/10.1007/s00521-019-04450-Z.

44. Sharma, V. S., Singh, G., \& Sørby, K. (2015). A review on minimum quantity lubrication for machining processes. Materials and Manufacturing Processes, 30(8), 935-953.

45. Rodriguez, V., Sukumaran, J., Schlarb, A. K., \& De Baets, P. (2016). Influence of solid lubricants on tribological properties of polyetheretherketone (PEEK). Tribology International, 103, $45-57$.

46. Bijwe, J., Kumar, K., Panda, J. N., Parida, T., \& Trivedi, P. (2016). Design and development of high performance tribo-composites based on synergism in two solid lubricants. Composites Part B Engineering, 94, 399-410. 
47. Belluco, W., \& De Chiffre, L. (2004). Performance evaluation of vegetable-based oils in drilling austenitic stainless steel. Journal of Materials Processing Technology, 148(2), 171-176.

48. Sen, B., Hussain, S. A. I., Mia, M., Mandal, U. K., \& Mondal, S. P. (2019). Selection of an ideal MQL-assisted milling condition: an NSGA-II-coupled TOPSIS approach for improving machinability of Inconel 690. The International Journal of Advanced Manufacturing Technology. https://doi.org/10.1007/s00170-01903620-6.

49. Ojolo, S., Amuda, M., Ogunmola, O., \& Ononiwu, C. (2008). Experimental determination of the effect of some straight biological oils on cutting force during cylindrical turning. Matéria (Rio de Janeiro), 13(4), 650-663.

50. Xavior, M. A., \& Adithan, M. (2009). Determining the influence of cutting fluids on tool wear and surface roughness during turning of AISI 304 austenitic stainless steel. Journal of Materials Processing Technology, 209(2), 900-909.

51. Kuram, E., Ozcelik, B., Demirbas, E., \& Sik, E. Effects of the cutting fluid types and cutting parameters on surface roughness and thrust force. In Proceedings of the world congress on engineering, 2010 (Vol. 2, pp. 978-988).

52. Mia, M., Gupta, M. K., Singh, G., Królczyk, G., \& Pimenov, D. Y. (2018). An approach to cleaner production for machining hardened steel using different cooling-lubrication conditions. Journal of Cleaner Production, 187, 1069-1081. https://doi. org/10.1016/j.jclepro.2018.03.279.

53. Wang, Y., Li, C., Zhang, Y., Yang, M., Li, B., Jia, D., et al. (2016). Experimental evaluation of the lubrication properties of the wheel/workpiece interface in minimum quantity lubrication (MQL) grinding using different types of vegetable oils. Journal of Cleaner Production, 127, 487-499. https://doi.org/10.1016/j. jclepro.2016.03.121.

54. Debnath, S., Reddy, M. M., \& Yi, Q. S. (2014). Environmental friendly cutting fluids and cooling techniques in machining: a review. Journal of Cleaner Production, 83, 33-47.

55. Jianzhong, W. J. Z. (2005). On formation and breakup of boundary lubricating layer [J]. Lubrication Engineering, 6, 001.

56. Eastman, J. A., Choi, S., Li, S., Yu, W., \& Thompson, L. (2001). Anomalously increased effective thermal conductivities of ethylene glycol-based nanofluids containing copper nanoparticles. Applied Physics Letters, 78(6), 718-720.

57. Yu, W., \& Xie, H. (2012). A review on nanofluids: preparation, stability mechanisms, and applications. Journal of Nanomaterials, 2012, 1 .

58. Rasheed, A., Khalid, M., Rashmi, W., Gupta, T., \& Chan, A. (2016). Graphene based nanofluids and nanolubricants-review of recent developments. Renewable and Sustainable Energy Reviews, 63, 346-362.

59. Li, B., Li, C., Zhang, Y., Wang, Y., Yang, M., Jia, D., et al. (2017). Effect of the physical properties of different vegetable oil-based nanofluids on MQLC grinding temperature of Ni-based alloy. The International Journal of Advanced Manufacturing Technology, 89(9-12), 3459-3474.

60. Maxwell, J. C. (1873). A treatise on electricity and magnetism (Vol. 1). Oxford: Clarendon Press.

61. Sen, B., Mia, M., Gupta, M. K., Rahman, M. A., Mandal, U. K., \& Mondal, S. P. (2019). Influence of Al2O3 and palm oil-mixed nano-fluid on machining performances of Inconel-690: iF-THEN rules-based FIS model in eco-benign milling. The International Journal of Advanced Manufacturing Technology. https://doi. org/10.1007/s00170-019-03814-y.

62. Wang, Y., Li, C., Zhang, Y., Yang, M., Zhang, X., Zhang, N., et al. (2017). Experimental evaluation on tribological performance of the wheel/workpiece interface in minimum quantity lubrication grinding with different concentrations of $\mathrm{Al} 2 \mathrm{O} 3$ nanofluids. Journal of Cleaner Production, 142, 3571-3583.
63. Bai, X., Li, C., Dong, L., \& Yin, Q. (2019). Experimental evaluation of the lubrication performances of different nanofluids for minimum quantity lubrication (MQL) in milling Ti-6Al-4V. The International Journal of Advanced Manufacturing Technology, 101(9-12), 2621-2632.

64. Alves, S., Barros, B., Trajano, M., Ribeiro, K., \& Moura, E. (2013). Tribological behavior of vegetable oil-based lubricants with nanoparticles of oxides in boundary lubrication conditions. Tribology International, 65, 28-36.

65. Zhang, Y., Li, C., Jia, D., Li, B., Wang, Y., Yang, M., et al. (2016). Experimental study on the effect of nanoparticle concentration on the lubricating property of nanofluids for MQL grinding of Ni-based alloy. Journal of Materials Processing Technology, 232, 100-115.

66. Munshi, A., Singh, V., Kumar, M., \& Singh, J. (2008). Effect of nanoparticle size on sessile droplet contact angle. Journal of Applied Physics, 103(8), 084315.

67. Abbas, A. T., Gupta, M. K., Soliman, M. S., Mia, M., Hegab, H., Luqman, M., et al. (2019). Sustainability assessment associated with surface roughness and power consumption characteristics in nanofluid MQL-assisted turning of AISI 1045 steel. The International Journal of Advanced Manufacturing Technology. https ://doi.org/10.1007/s00170-019-04325-6.

68. Wang, Y., Li, C., Zhang, Y., Yang, M., Li, B., Dong, L., et al. (2018). Processing characteristics of vegetable oil-based nanofluid MQL for grinding different workpiece materials. International Journal of Precision Engineering and ManufacturingGreen Technology, 5(2), 327-339. https://doi.org/10.1007/s4068 4-018-0035-4.

69. Sarafraz, M., Hormozi, F., \& Nikkhah, V. (2016). Thermal performance of a counter-current double pipe heat exchanger working with $\mathrm{COOH}-\mathrm{CNT} /$ water nanofluids. Experimental Thermal and Fluid Science, 78, 41-49.

70. Vasu, V., \& Pradeep Kumar Reddy, G. (2011). Effect of minimum quantity lubrication with $\mathrm{Al} 2 \mathrm{O} 3$ nanoparticles on surface roughness, tool wear and temperature dissipation in machining Inconel 600 alloy. Proceedings of the Institution of Mechanical Engineers, Part N: Journal of Nanoengineering and Nanosystems, 225(1), 3-16.

71. Mandal, B., Singh, R., Das, S., \& Banerjee, S. (2012). Development of a grinding fluid delivery technique and its performance evaluation. Materials and Manufacturing Processes, 27(4), 436-442.

72. Setti, D., Ghosh, S., \& Rao, P. V. Application of nano cutting fluid under minimum quantity lubrication (MQL) technique to improve grinding of Ti-6Al-4V alloy. In Proceedings of World Academy of Science, Engineering and Technology, 2012 (Vol. 70, pp. 512-516): World Academy of Science, Engineering and Technology.

73. Mao, C., Zou, H., Huang, X., Zhang, J., \& Zhou, Z. (2013). The influence of spraying parameters on grinding performance for nanofluid minimum quantity lubrication. The International Journal of Advanced Manufacturing Technology, 64(9-12), 1791-1799.

74. Mao, C., Zou, H., Zhou, X., Huang, Y., Gan, H., \& Zhou, Z. (2014). Analysis of suspension stability for nanofluid applied in minimum quantity lubricant grinding. The International Journal of Advanced Manufacturing Technology, 71(9-12), 2073-2081.

75. Sharma, A. K., Singh, R. K., Dixit, A. R., \& Tiwari, A. K. (2016). Characterization and experimental investigation of Al2O3 nanoparticle based cutting fluid in turning of AISI 1040 steel under minimum quantity lubrication (MQL). Materials Today: Proceedings, 3(6), 1899-1906.

76. Padmini, R., Krishna, P. V., \& Rao, G. K. M. (2014). Performance assessment of micro and nano solid lubricant suspensions 
in vegetable oils during machining. Proceedings of the Institution of Mechanical Engineers, Part B: Journal of Engineering Manufacture, 229(12), 2196-2204. https://doi.org/10.1177/09544 05414548465.

77. Zhang, D., Li, C., Zhang, Y., Jia, D., \& Zhang, X. (2015). Experimental research on the energy ratio coefficient and specific grinding energy in nanoparticle jet MQL grinding. The International Journal of Advanced Manufacturing Technology, 78(5-8), 1275-1288.

78. Padmini, R., Krishna, P. V., \& Rao, G. K. M. (2016). Effectiveness of vegetable oil based nanofluids as potential cutting fluids in turning AISI 1040 steel. Tribology International, 94, 490-501.

79. Nam, J., \& Lee, S. W. (2018). Machinability of titanium alloy (Ti-6Al-4V) in environmentally-friendly micro-drilling process with nanofluid minimum quantity lubrication using nanodiamond particles. International Journal of Precision Engineering and Manufacturing-Green Technology, 5(1), 29-35. https://doi. org/10.1007/s40684-018-0003-z.

80. Nam, J. S., Lee, P.-H., \& Lee, S. W. (2011). Experimental characterization of micro-drilling process using nanofluid minimum quantity lubrication. International Journal of Machine Tools and Manufacture, 51(7-8), 649-652.

81. Nam, J. S., Kim, D. H., \& Lee, S. W. A parametric analysis on micro-drilling process with nanofluid minimum quantity lubrication. In ASME 2013 International Manufacturing Science and Engineering Conference collocated with the 41st North American Manufacturing Research Conference, 2013 (pp. V002T004A016-V002T004A016): American Society of Mechanical Engineers.

82. Sarhan, A. A., Sayuti, M., \& Hamdi, M. (2012). Reduction of power and lubricant oil consumption in milling process using a new $\mathrm{SiO} 2$ nanolubrication system. The International Journal of Advanced Manufacturing Technology, 63(5-8), 505-512.

83. Sayuti, M., Sarhan, A. A., \& Salem, F. (2014). Novel uses of $\mathrm{SiO} 2$ nano-lubrication system in hard turning process of hardened steel AISI4140 for less tool wear, surface roughness and oil consumption. Journal of Cleaner Production, 67, 265-276.

84. Ooi, M. E., Sayuti, M., \& Sarhan, A. A. (2015). Fuzzy logicbased approach to investigate the novel uses of nano suspended lubrication in precise machining of aerospace AL tempered grade 6061. Journal of Cleaner Production, 89, 286-295.

85. You, J., \& Gao, Y. A study of carbon nanotubes as cutting grains for nano machining. In Advanced Materials Research, 2009 (Vol. 76, pp. 502-507): Trans Tech Publ.

86. Rao, S. N., Satyanarayana, B., \& Venkatasubbaiah, K. (2011). Experimental estimation of tool wear and cutting temperatures in MQL using cutting fluids with CNT inclusion. International Journal of Engineering Science and Technology, 3(4).

87. Prabhu, S., \& Vinayagam, B. K. (2012). AFM investigation in grinding process with nanofluids using Taguchi analysis. The International Journal of Advanced Manufacturing Technology, 60(1-4), 149-160.

88. Sayuti, M., Sarhan, A. A., Tanaka, T., Hamdi, M., \& Saito, Y. (2013). Cutting force reduction and surface quality improvement in machining of aerospace duralumin AL-2017-T4 using carbon onion nanolubrication system. The International Journal of Advanced Manufacturing Technology, 65(9-12), 1493-1500.

89. Huang, H., Tu, J., Gan, L., \& Li, C. (2006). An investigation on tribological properties of graphite nanosheets as oil additive. Wear, 261(2), 140-144.

90. Marcon, A., Melkote, S., Kalaitzidou, K., \& DeBra, D. (2010). An experimental evaluation of graphite nanoplatelet based lubricant in micro-milling. CIRP Annals, 59(1), 141-144.

91. Alberts, M., Kalaitzidou, K., \& Melkote, S. (2009). An investigation of graphite nanoplatelets as lubricant in grinding.
International Journal of Machine Tools and Manufacture, 49(12-13), 966-970.

92. Ravuri, B. P., Goriparthi, B. K., Revuru, R. S., \& Anne, V. G. (2016). Performance evaluation of grinding wheels impregnated with graphene nanoplatelets. The International Journal of Advanced Manufacturing Technology, 85(9-12), 2235-2245.

93. Pavan, R. B., Gopal, A. V., Amrita, M., \& Bhanu, K. G. (2017). Experimental investigation of graphene nanoplatelets-based minimum quantity lubrication in grinding Inconel 718. Proceedings of the Institution of Mechanical Engineers, Part B: Journal of Engineering Manufacture. https://doi.org/10.1177/09544 05417728311.

94. Kwon, P., \& Drzal, L. T. (2015). Nanoparticle graphite-based minimum quantity lubrication method and composition. Google Patents.

95. Wang, Y., Li, C., Zhang, Y., Li, B., Yang, M., Zhang, X., et al. (2016). Experimental evaluation of the lubrication properties of the wheel/workpiece interface in MQL grinding with different nanofluids. Tribology International, 99, 198-210.

96. Beyth, N., Houri-Haddad, Y., Domb, A., Khan, W., \& Hazan, R. (2015). Alternative antimicrobial approach: nano-antimicrobial materials. Evidence-based complementary and alternative medicine, 2015.

97. Marsalek, R. (2014). Particle size and zeta potential of $\mathrm{ZnO}$. APCBEE procedia, 9, 13-17.

98. Salehi, J., Heyhat, M., \& Rajabpour, A. (2013). Enhancement of thermal conductivity of silver nanofluid synthesized by a onestep method with the effect of polyvinylpyrrolidone on thermal behavior. Applied Physics Letters, 102(23), 231907.

99. Tseng, K.-H., Lee, H.-L., Liao, C.-Y., Chen, K.-C., \& Lin, H.-S. (2013). Rapid and efficient synthesis of silver nanofluid using electrical discharge machining. Journal of Nanomaterials, 2013, 1.

100. Lee, K., Hwang, Y., Cheong, S., Choi, Y., Kwon, L., Lee, J., et al. (2009). Understanding the role of nanoparticles in nano-oil lubrication. Tribology Letters, 35(2), 127-131.

101. Mia, M., Dey, P. R., Hossain, M. S., Arafat, M. T., Asaduzzaman, M., Shoriat Ullah, M., et al. (2018). Taguchi S/N based optimization of machining parameters for surface roughness, tool wear and material removal rate in hard turning under MQL cutting condition. Measurement, 122, 380-391. https://doi.org/10.1016/j. measurement.2018.02.016.

102. Thakur, D., Ramamoorthy, B., \& Vijayaraghavan, L. (2009). Optimization of minimum quantity lubrication parameters in high speed turning of superalloy Inconel 718 for sustainable development. Signal, 20(300), 200.

103. Che Haron, C. H., Ghani, J. A., Kasim, M. S., Soon, T., Ibrahim, G. A., \& Sulaiman, M. A. Surface intergrity of Inconel 718 under MQL condition. In Advanced Materials Research, 2011 (Vol. 150, pp. 1667-1672): Trans Tech Publ.

104. Liu, Z., An, Q., Xu, J., Chen, M., \& Han, S. (2013). Wear performance of (nc-AlTiN)/(a-Si3N4) coating and (nc-AlCrN)/ (a-Si3N4) coating in high-speed machining of titanium alloys under dry and minimum quantity lubrication (MQL) conditions. Wear, 305(1-2), 249-259.

105. Liu, Z., Xu, J., Han, S., \& Chen, M. (2013). A coupling method of response surfaces (CRSM) for cutting parameters optimization in machining titanium alloy under minimum quantity lubrication (MQL) condition. International Journal of Precision Engineering and Manufacturing, 14(5), 693-702.

106. Stephenson, D., Skerlos, S. J., King, A. S., \& Supekar, S. D. (2014). Rough turning Inconel 750 with supercritical CO2-based minimum quantity lubrication. Journal of Materials Processing Technology, 214(3), 673-680.

107. Sarıkaya, M., \& Güllü, A. (2015). Multi-response optimization of minimum quantity lubrication parameters using Taguchi-based 
grey relational analysis in turning of difficult-to-cut alloy Haynes 25. Journal of Cleaner Production, 91, 347-357.

108. Khan, A., Jamil, M., Mia, M., Pimenov, D., Gasiyarov, V., Gupta, M., et al. (2018). Multi-objective optimization for grinding of AISI D2 steel with $\mathrm{Al}_{2} \mathrm{O}_{3}$ wheel under MQL. Materials, 11(11), 2269. https://doi.org/10.3390/ma11112269.

109. Sadeghi, M., Haddad, M., Tawakoli, T., \& Emami, M. (2009). Minimal quantity lubrication-MQL in grinding of Ti-6Al-4V titanium alloy. The International Journal of Advanced Manufacturing Technology, 44(5-6), 487-500.

110. Barczak, L. M., Batako, A. D. L., \& Morgan, M. N. (2010). A study of plane surface grinding under minimum quantity lubrication (MQL) conditions. International Journal of Machine Tools and Manufacture, 50(11), 977-985. https://doi.org/10.1016/j. ijmachtools.2010.07.005.

111. de Jesus Oliveira, D., Guermandi, L. G., Bianchi, E. C., Diniz, A. E., de Aguiar, P. R., \& Canarim, R. C. (2012). Improving minimum quantity lubrication in CBN grinding using compressed air wheel cleaning. Journal of Materials Processing Technology, 212(12), 2559-2568.

112. Li, K.-M., \& Lin, C.-P. (2012). Study on minimum quantity lubrication in micro-grinding. The International Journal of Advanced Manufacturing Technology, 62(1-4), 99-105.

113. Balan, A., Vijayaraghavan, L., \& Krishnamurthy, R. (2013). Minimum quantity lubricated grinding of Inconel 751 alloy. Materials and Manufacturing Processes, 28(4), 430-435.

114. Hadad, M., \& Hadi, M. (2013). An investigation on surface grinding of hardened stainless steel S34700 and aluminum alloy AA6061 using minimum quantity of lubrication (MQL) technique. The International Journal of Advanced Manufacturing Technology, 68(9-12), 2145-2158.

115. Rabiei, F., Rahimi, A., Hadad, M., \& Ashrafijou, M. (2015). Performance improvement of minimum quantity lubrication (MQL) technique in surface grinding by modeling and optimization. Journal of Cleaner Production, 86, 447-460.

116. Sridharan, U., \& Malkin, S. (2009). Effect of minimum quantity lubrication (MQL) with nanofluid on grinding behavior and thermal distortion. Trans NAMRI/SME, 37, 629-636.

117. Lee, P.-H., Lee, S. W., Lim, S.-H., Lee, S.-H., Ko, H. S., \& Shin, S.-W. (2015). A study on thermal characteristics of micro-scale grinding process using nanofluid minimum quantity lubrication (MQL). International journal of precision engineering and manufacturing, 16(9), 1899-1909.

118. Sun, J., Wong, Y., Rahman, M., Wang, Z., Neo, K., Tan, C., et al. (2006). Effects of coolant supply methods and cutting conditions on tool life in end milling titanium alloy. Machining Science and Technology, 10(3), 355-370.

119. Li, H., Zeng, H., \& Chen, X. (2006). An experimental study of tool wear and cutting force variation in the end milling of Inconel 718 with coated carbide inserts. Journal of Materials Processing Technology, 180(1-3), 296-304.

120. Da Silva, R., Vieira, J., Cardoso, R., Carvalho, H., Costa, E., Machado, A., et al. (2011). Tool wear analysis in milling of medium carbon steel with coated cemented carbide inserts using different machining lubrication/cooling systems. Wear, 271(910), 2459-2465.

121. Liu, Z., Cai, X., Chen, M., \& An, Q. (2011). Investigation of cutting force and temperature of end-milling Ti-6Al-4V with different minimum quantity lubrication (MQL) parameters. Proceedings of the Institution of Mechanical Engineers, Part B: Journal of Engineering Manufacture, 225(8), 1273-1279.

122. Zhang, S., Li, J., \& Wang, Y. (2012). Tool life and cutting forces in end milling Inconel 718 under dry and minimum quantity cooling lubrication cutting conditions. Journal of Cleaner Production, 32, 81-87.
123. Mia, M. (2018). Mathematical modeling and optimization of MQL assisted end milling characteristics based on RSM and Taguchi method. Measurement, 121, 249-260.

124. Davim, J., Sreejith, P., Gomes, R., \& Peixoto, C. (2006). Experimental studies on drilling of aluminium (AA1050) under dry, minimum quantity of lubricant, and flood-lubricated conditions. Proceedings of the Institution of Mechanical Engineers, Part B: Journal of Engineering Manufacture, 220(10), 1605-1611.

125. Bhowmick, S., Lukitsch, M. J., \& Alpas, A. T. (2010). Dry and minimum quantity lubrication drilling of cast magnesium alloy (AM60). International Journal of Machine Tools and Manufacture, 50(5), 444-457.

126. Bhowmick, S., \& Alpas, A. (2011). The role of diamond-like carbon coated drills on minimum quantity lubrication drilling of magnesium alloys. Surface \& Coatings Technology, 205(23-24), 5302-5311.

127. Rahim, E. A., \& Sasahara, H. (2011). An analysis of surface integrity when drilling inconel 718 using palm oil and synthetic ester under MQL condition. Machining Science and Technology, 15(1), 76-90.

128. Fox-Rabinovich, G., Dasch, J., Wagg, T., Yamamoto, K., Veldhuis, S., Dosbaeva, G., et al. (2011). Cutting performance of different coatings during minimum quantity lubrication drilling of aluminum silicon B319 cast alloy. Surface \& Coatings Technology, 205(16), 4107-4116.

129. Kilickap, E., Huseyinoglu, M., \& Yardimeden, A. (2011). Optimization of drilling parameters on surface roughness in drilling of AISI 1045 using response surface methodology and genetic algorithm. The International Journal of Advanced Manufacturing Technology, 52(1-4), 79-88.

130. Brinksmeier, E., Pecat, O., \& Rentsch, R. (2015). Quantitative analysis of chip extraction in drilling of Ti6Al4 V. CIRP Annals, 64(1), 93-96.

131. Wang, Z., Rahman, M., Wong, Y., Neo, K., Sun, J., Tan, C., et al. (2009). Study on orthogonal turning of titanium alloys with different coolant supply strategies. The International Journal of Advanced Manufacturing Technology, 42(7-8), 621.

132. Pereira, O., Rodríguez, A., Barreiro, J., Fernández-Abia, A. I., $\&$ de Lacalle, L. N. L. (2017). Nozzle design for combined use of MQL and cryogenic gas in machining. International Journal of Precision Engineering and Manufacturing-Green Technology, 4(1), 87-95. https://doi.org/10.1007/s40684-017-0012-3.

133. Grguraš, D., Sterle, L., Krajnik, P., \& Pušavec, F. (2019). A novel cryogenic machining concept based on a lubricated liquid carbon dioxide. International Journal of Machine Tools and Manufacture, 145, 103456. https://doi.org/10.1016/j.ijmac htools.2019.103456.

134. Huang, S., Lv, T., Wang, M., \& Xu, X. (2018). Effects of machining and oil mist parameters on electrostatic minimum quantity lubrication-EMQL turning process. International Journal of Precision Engineering and Manufacturing-Green Technology, 5(2), 317-326. https://doi.org/10.1007/s4068 4-018-0034-5.

135. Libardi, A., Schmid, S., Sen, M., \& Schneider, W. (2013). Evaluation of ionic fluids as lubricants in manufacturing. Journal of Manufacturing Processes, 15(4), 414-418.

136. Davis, B., Schueller, J. K., \& Huang, Y. (2015). Study of ionic liquid as effective additive for minimum quantity lubrication during titanium machining. Manufacturing Letters, 5, 1-6.

137. Goindi, G. S., Chavan, S. N., Mandal, D., Sarkar, P., \& Jayal, A. D. (2015). Investigation of ionic liquids as novel metalworking fluids during minimum quantity lubrication machining of a plain carbon steel. Procedia CIRP, 26, 341-345.

138. Pham, M.-Q., Yoon, H.-S., Khare, V., \& Ahn, S.-H. (2014). Evaluation of ionic liquids as lubricants in micro milling-process capability and sustainability. Journal of Cleaner Production, 76, 167-173. 
139. Sani, A. S. A., Rahim, E. A., Sharif, S., \& Sasahara, H. (2019). Machining performance of vegetable oil with phosphonium-and ammonium-based ionic liquids via MQL technique. Journal of Cleaner Production, 209, 947-964.

140. Salaam, H., Taha, Z., Ya, T., \& Shah, T. M. Y. Minimum quantity lubrication (MQL) using Ranque-Hilsch vortex tube (RHVT) for sustainable machining. In Applied Mechanics and Materials, 2012 (Vol. 217): Trans Tech Publ.

141. Kirmaci, V. (2009). Exergy analysis and performance of a counter flow Ranque-Hilsch vortex tube having various nozzle numbers at different inlet pressures of oxygen and air. International Journal of Refrigeration, 32(7), 1626-1633.

142. Selek, M., Tasdemir, S., Dincer, K., \& Baskaya, S. (2011). Experimental examination of the cooling performance of Ranque-Hilsch vortex tube on the cutting tool nose point of the turret lathe through infrared thermography method. International Journal of Refrigeration, 34(3), 807-815.

143. Liu, J., \& Chou, Y. K. (2007). On temperatures and tool wear in machining hypereutectic Al-Si alloys with vortex-tube cooling. International Journal of Machine Tools and Manufacture, 47(3-4), 635-645.

144. Boswell, B., \& Islam, M. N. (2013). The challenge of adopting minimal quantities of lubrication for end milling aluminium. In IAENG Transactions on Engineering Technologies (pp. 713724). Dordrecht: Springer.

145. Mia, M., Singh, G., Gupta, M. K., \& Sharma, V. S. (2018). Influence of Ranque-Hilsch vortex tube and nitrogen gas assisted MQL in precision turning of $\mathrm{Al}$ 6061-T6. Precision Engineering, 53, 289-299. https://doi.org/10.1016/j.precisioneng.2018.04.011.

146. Dhar, N., Kishore, N. S., Paul, S., \& Chattopadhyay, A. (2002). The effects of cryogenic cooling on chips and cutting forces in turning AISI 1040 and AISI 4320 steels. Proceedings of the Institution of Mechanical Engineers, Part B: Journal of Engineering Manufacture, 216(5), 713-724.

147. Venugopal, K., Tawade, R., Prashanth, P., Paul, S., \& Chattopadhyay, A. (2003). Turning of titanium alloy with TiB2-coated carbides under cryogenic cooling. Proceedings of the Institution of Mechanical Engineers, Part B: Journal of Engineering Manufacture, 217(12), 1697-1707.

148. Ravi, S., \& Kumar, M. P. (2011). Experimental investigations on cryogenic cooling by liquid nitrogen in the end milling of hardened steel. Cryogenics, 51(9), 509-515.

149. Huang, X., Zhang, X., Mou, H., Zhang, X., \& Ding, H. (2014). The influence of cryogenic cooling on milling stability. Journal of Materials Processing Technology, 214(12), 3169-3178.

150. Manimaran, G., \& Venkatasamy, R. (2014). Influence of cryogenic cooling on surface grinding of stainless steel 316. Cryogenics, 59, 76-83.

151. Dix, M., Wertheim, R., Schmidt, G., \& Hochmuth, C. (2014). Modeling of drilling assisted by cryogenic cooling for higher efficiency. CIRP Annals-Manufacturing Technology, 63(1), 73-76.

152. Su, Y., He, N., \& Li, L. Effect of cryogenic minimum quantity lubrication (CMQL) on cutting temperature and tool wear in high-speed end milling of titanium alloys. In Applied Mechanics and Materials, 2010 (Vol. 34, pp. 1816-1821): Trans Tech Publ.

153. Yuan, S., Yan, L., Liu, W., \& Liu, Q. (2011). Effects of cooling air temperature on cryogenic machining of Ti-6Al-4V alloy. Journal of Materials Processing Technology, 211(3), 356-362.

154. Zhang, S., Li, J., \& Lv, H. (2014). Tool wear and formation mechanism of white layer when hard milling H13 steel under different cooling/lubrication conditions. Advances in Mechanical Engineering, 6, 949308.

155. Su, Y., He, N., Li, L., Iqbal, A., Xiao, M., Xu, S., et al. (2007). Refrigerated cooling air cutting of difficult-to-cut materials. International Journal of Machine Tools and Manufacture, 47(6), 927-933.
156. Busch, K., Hochmuth, C., Pause, B., Stoll, A., \& Wertheim, R. (2016). Investigation of cooling and lubrication strategies for machining high-temperature alloys. Procedia CIRP, 41, 835-840. https://doi.org/10.1016/j.procir.2015.10.005.

157. Sartori, S., Ghiotti, A., \& Bruschi, S. (2017). Hybrid lubricating/ cooling strategies to reduce the tool wear in finishing turning of difficult-to-cut alloys. Wear, 376-377, 107-114. https://doi. org/10.1016/j.wear.2016.12.047.

158. Pusavec, F., Deshpande, A., Yang, S., M'Saoubi, R., Kopac, J., Dillon, O. W., et al. (2014). Sustainable machining of high temperature Nickel alloy-Inconel 718: part 1-predictive performance models. Journal of Cleaner Production, 81, 255-269.

159. Pusavec, F., Deshpande, A., Yang, S., M'Saoubi, R., Kopac, J., Dillon, O. W., et al. (2015). Sustainable machining of high temperature Nickel alloy-Inconel 718: part 2-chip breakability and optimization. Journal of Cleaner Production, 87, 941-952.

160. Faverjon, P., Rech, J., Valiorgue, F., \& Orset, M. (2015). Optimization of a drilling sequence under MQL to minimize the thermal distortion of a complex aluminum part. Production Engineering, 9(4), 505-515.

161. Clarens, A. F., Hayes, K. F., \& Skerlos, S. J. (2006). Feasibility of metalworking fluids delivered in supercritical carbon dioxide. Journal of Manufacturing Processes, 8(1), 47-53.

162. Sanchez, J., Pombo, I., Alberdi, R., Izquierdo, B., Ortega, N., Plaza, S., et al. (2010). Machining evaluation of a hybrid MQL$\mathrm{CO} 2$ grinding technology. Journal of Cleaner Production, 18(18), 1840-1849.

163. García, E., Méresse, D., Pombo, I., Dubar, M., \& Sánchez, J. (2016). Role of frozen lubricant film on tribological behaviour and wear mechanisms in grinding. The International Journal of Advanced Manufacturing Technology, 82(5-8), 1017-1027.

164. Boswell, B., Islam, M. N., Davies, I. J., Ginting, Y., \& Ong, A. K. (2017). A review identifying the effectiveness of minimum quantity lubrication (MQL) during conventional machining. The International Journal of Advanced Manufacturing Technology, 92(1-4), 321-340.

165. Mulyadi, I. (2013). Improving the performance of minimum quantity lubrication in high speed milling and environmental performance analysis, $\mathrm{PhD}$ thesis, The University of Manchester, Manchester, UK

166. Pereira, O., Rodríguez, A., Fernández-Abia, A., Barreiro, J., \& de Lacalle, L. L. (2016). Cryogenic and minimum quantity lubrication for an eco-efficiency turning of AISI 304. Journal of Cleaner Production, 139, 440-449.

167. Skerlos, S. J., Hayes, K. F., Clarens, A. F., \& Zhao, F. (2008). Current advances in sustainable metalworking fluids research. International journal of sustainable manufacturing, 1(1-2), 180-202.

168. Benedicto, E., Carou, D., \& Rubio, E. (2017). Technical, economic and environmental review of the lubrication/cooling systems used in machining processes. Procedia Engineering, 184, 99-116.

169. Tazehkandi, A. H., Shabgard, M., \& Pilehvarian, F. (2015). Application of liquid nitrogen and spray mode of biodegradable vegetable cutting fluid with compressed air in order to reduce cutting fluid consumption in turning Inconel 740. Journal of Cleaner Production, 108, 90-103.

170. Shokoohi, Y., \& Shekarian, E. (2015). Application of nanofluids in machining processes-a review. Journal of Nanoscience and Technology, 28, 59-63.

171. Boubekri, N., Shaikh, V., \& Foster, P. R. (2010). A technology enabler for green machining: minimum quantity lubrication (MQL). Journal of Manufacturing Technology Management, 21(5), 556-566.

172. Weinert, K., Inasaki, I., Sutherland, J., \& Wakabayashi, T. (2004). Dry machining and minimum quantity lubrication. CIRP Annals, 53(2), 511-537. 
173. Sayuti, M., Erh, O. M., Sarhan, A. A., \& Hamdi, M. (2014). Investigation on the morphology of the machined surface in end milling of aerospace AL6061-T6 for novel uses of $\mathrm{SiO}_{2}$ nanolubrication system. Journal of Cleaner Production, 66, 655-663.

Publisher's Note Springer Nature remains neutral with regard to jurisdictional claims in published maps and institutional affiliations.

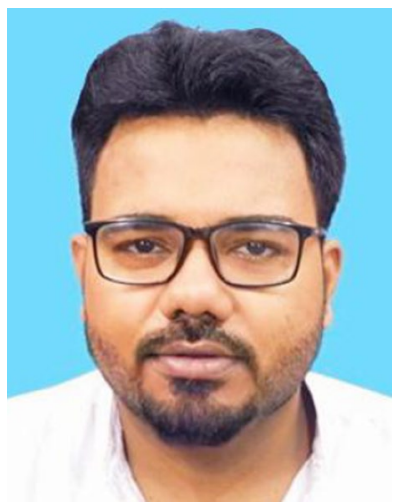

Binayak Sen is a Ph.D. candidate in the Department of Production Engineering at the National Institute of Technology, Agartala. He received his M.Tech. degree in Production Engineering from the same institute. His research interest is Eco-benign machining of heat resistive superalloys.

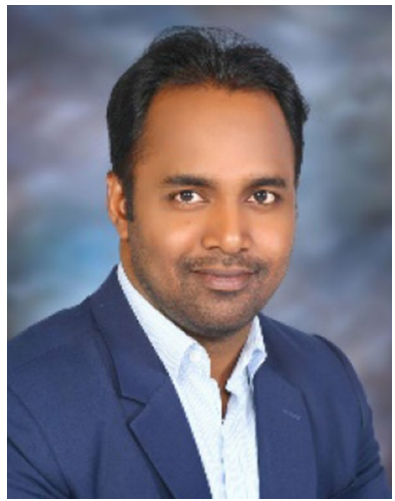

Mozammel Mia is a $\mathrm{Ph} . \mathrm{D}$. researcher in the Department of Mechanical Engineering of Imperial College London, South Kensington, London, United Kingdom. Before that, now on study leave, he served as an Assistant Professor in the Department of Mechanical and Production Engineering of Ahsanullah University of Science and Technology, Dhaka, Bangladesh. His major area of research interest is Advanced Manufacturing like Machining, Additive Manufacturing, Metal Forming etc. with multi-disciplinary analysis like Mathematical modeling, Optimization and Prediction modeling. He has authored and coauthored above 60 articles in indexed journals.

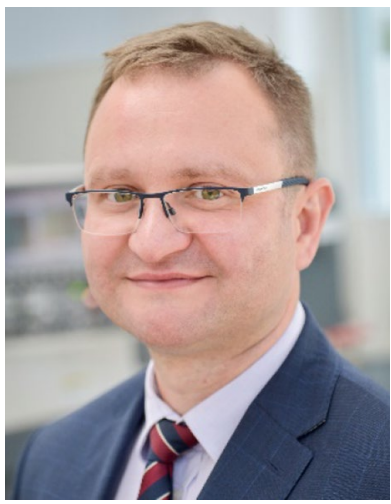

G. M. Krolczyk is a Professor at Opole University of Technology. Author \& co-author of 180 scientific publications (100 JCR papers), as well as nearly 30 studies and industrial applications. His main directions of scientific activity are analysis and improvement of manufacturing processes, surface metrology and surface engineering. His research focuses on sustainable manufacturing as a tool for the practical implementation of the concept of social responsibility in the area of machining.

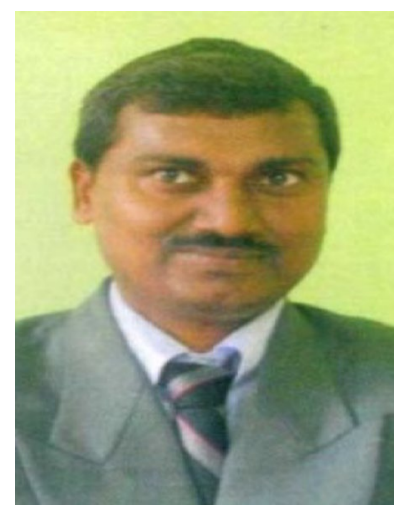

Dr. Uttam Kumar Mandal is an Assistant Professor in the Department of Production Engineering at National Institute of Technology, Agartala. $\mathrm{He}$ received Ph.D. from Jadavpur University, Kolkata, West Bengal. He is having 17 years of teaching experience, and he is also a reviewer of some of the well-known journals. His current research interests include Green machining as well as Fuzzy optimization.

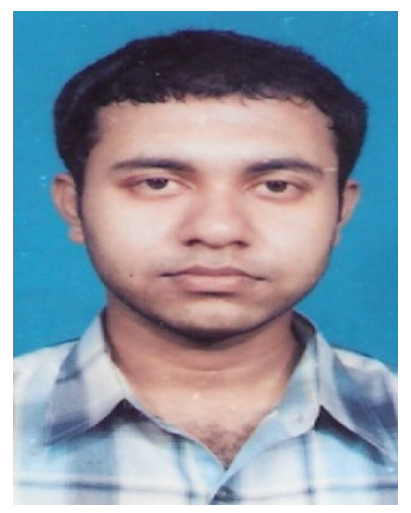

Sankar Prasad Mondal is an Assistant Professor in the Department of Applied Science, Maulana Abul Kalam Azad University of Technology, West Bengal, India. Before serving in the present work, he was an Assistant Professor in the Department of Mathematics Midnapore College (Autonomous) and National Institute of Technology, Agartala for five years. He is having five years of research experience in the field of operations research, differential equation, fuzzy sets, mathematical biology, and fuzzy differential equation. 